Article

\title{
Proteomic Analysis of the Function of a Novel Cold-Regulated Multispanning Transmembrane Protein COR413-PM1 in Arabidopsis
}

\author{
Chen Su 1,2,3, Kai Chen 2,3,4, Qingqian Ding 2,3, Yongying Mou ${ }^{2}$, Rui Yang 1,2,3, Mengjie Zhao ${ }^{2}$, \\ Bo Ma ${ }^{2}$, Zhaoshi $\mathrm{Xu}^{2,3}$, Youzhi Ma ${ }^{2,3}$, Yinghong Pan ${ }^{2, *}$, Ming Chen ${ }^{2,3, *}$ and Yajun $\mathrm{Xi}^{1,2,3, *}$ \\ 1 College of Agronomy, Northwest A\&F University, Yangling 712100, China; suchen1213@163.com (C.S.); \\ 18334534481@163.com (R.Y.) \\ 2 Institute of Crop Sciences, Chinese Academy of Agricultural Sciences (CAAS)/National Key Facility for \\ Crop Gene Resources and Genetic Improvement, Beijing 100081, China; chenkai8@vip.163.com (K.C.); \\ dingqingqian0215@163.com (Q.D.); mu_yongying@163.com (Y.M.); zhao_mengjie0815@163.com (M.Z.); \\ mabo8686@163.com (B.M.); xuzhaoshi@caas.cn (Z.X.); mayouzhi@caas.cn (Y.M.) \\ 3 Key Laboratory of Biology and Genetic Improvement of Triticeae Crops, Ministry of Agriculture, \\ Beijing 100081, China \\ 4 College of Life Science, Jilin Agricultural University, Changchun 130118, China \\ * Correspondence: panyinghong@caas.cn (Y.P.); chenming02@caas.cn (M.C.); xiyajun2002@126.com (Y.X.); \\ Tel.: +86-010-8210-8750 (M.C.)
}

Received: 31 July 2018; Accepted: 26 August 2018; Published: 29 August 2018

\begin{abstract}
The plasma membrane is the first subcellular organ that senses low temperature, and it includes some spanning transmembrane proteins that play important roles in cold regulation. COR413-PM1 is a novel multispanning transmembrane cold-regulated protein; however, the related functions are not clear in Arabidopsis. We found the tolerance to freezing stress of cor413-pm1 was lower than wild-type (WT). A proteomics method was used to analyze the differentially abundant proteins (DAPs) between cor413-pm1 and WT. A total of 4143 protein groups were identified and 3139 were accurately quantitated. The DAPs associated with COR413-PM1 and freezing treatment were mainly involved in the metabolism of fatty acids, sugars, and purine. Quantitative real-time PCR (qRT-PCR) confirmed the proteomic analysis results of four proteins: fatty acid biosynthesis 1 (FAB1) is involved in fatty acid metabolism and might affect the plasma membrane structure; fructokinase 3 (FRK3) and sucrose phosphate synthase A1 (SPSA1) play roles in sugar metabolism and may influence the ability of osmotic adjustment under freezing stress; and GLN phosphoribosyl pyrophosphate amidotransferase 2 (ASE2) affects freezing tolerance through purine metabolism pathways. In short, our results demonstrate that the multispanning transmembrane protein COR413-PM1 regulates plant tolerance to freezing stress by affecting the metabolism of fatty acids, sugars, and purine in Arabidopsis.
\end{abstract}

Keywords: freezing stress; COR413-PM1; gene function; proteomic analysis; Arabidopsis

\section{Introduction}

Cold stress tolerance is essential for plant development and environmental acclimation. Cold stress refers to chilling $\left(0-20^{\circ} \mathrm{C}\right)$ and /or freezing $\left(<0{ }^{\circ} \mathrm{C}\right)$ temperatures that can induce ice formation in plant tissues, damage the normal function and structure of cells, and limit plant growth and development, resulting in significant losses in agricultural production [1,2]. Plants acquiring cold stress tolerance upon prior exposure to low nonfreezing temperatures is known as cold acclimation. Cold acclimation involves numerous changes in structures specific to the plasma membrane, 
the reprogramming of regulated metabolism, and gene expression [3-5]. Significant progress has been made in the past several decades in describing the plant transcriptome regulating network associated with cold stress from exposure to chilling and freezing temperatures, and this work has significantly contributed to our understanding of tolerance mechanisms to cold stress [1]. The C-repeat Binding Factor/DRE Binding Factor (CBF/DREB) controls the expression of cold-induced genes, and its transcriptional regulatory cascade is widely recognized as the main cold signaling pathway [4]. The CBF transcription factors (CBF1/DREB1b, CBF2/DREB1c, and CBF3/DREB1a) together with an APETALA2/ethylene response factor (AP2) DNA binding domain play a key role in the cold signaling pathway in plants $[6,7]$. This signal transduction causes a series of downstream responses to cold. After exposure to cold stress, except for transcriptional level changes, plants make large changes in their physiological and biochemical metabolisms [1], such as metabolism of carbohydrates, proteins, and amino acids, and in signal transduction [8,9]. In Arabidopsis, the downregulation of photosynthesis and hormonal responses is associated with enhanced freezing tolerance [10]. The accumulation of soluble sugars is a fundamental component of enhanced freezing tolerance [11]. On the other hand, the signaling system of low temperature acclimation crosses with other signal systems, such as those of drought or high salt stress, due to the fact that they share many common features including cellular dehydration, which can cause injury to plants after exposure to freezing temperatures, drought, or salt $[11,12]$. Plants have evolved various mechanisms for cold sensing and stress signal transduction, and these varied mechanisms interact to produce cold tolerance.

In the process of cold acclimation in plants, the expression of cold response genes plays an important role [13]. A study using an Affymetrix GeneChips assay showed that $3.9 \%$ of genes in Arabidopsis were determined to be cold responsive, with 655 upregulated and 284 downregulated under low-temperature conditions [14]. The expression of cold-regulated (COR) genes can be induced by low temperatures [15], while some genes are also induced by drought and abscisic acid (ABA) [16]. The expression of COR gene COR29A, which is present in Arabidopsis, is induced not only by cold but also by drought stress and ABA treatment [17]. BnCOR25 is significantly induced by both cold stress and ABA treatment in Brassica napus [18]. At present, most of the genes involved in plant response to low-temperature stress are located in the cytoplasm or nucleus, and a few studies have reported membrane localization proteins involved in plants' response to low temperatures. The COR413-like protein containing five putative transmembrane domains (TMD) belongs to a subfamily of the COR protein family. The COR413 gene subfamily encodes two distinct groups of multispanning transmembrane proteins including COR413-PM proteins targeted to the plasma membrane and COR413-TM proteins targeted to the thylakoid membrane [19]. COR413 is not only induced by freezing temperatures but also by water stress and ABA treatment [20]. Low-temperature stress can influence the composition of the plasma membrane by reducing cellular membrane fluidity and increasing rigidity [21]. The structural changes associated with plasma membrane rigidification can lead to the expression of COR and cold-acclimation-related genes in alfalfa (Medicago sativa) and B. napus [21,22]. For example, for two late embryogenesis abundant (LEA) proteins, COR15A and COR15B, expression is highly cold induced, and their proteins are able to interact with membranes and act as membrane protectants [23]. The expression of COR15A, as a hydrophilic protein gene, increases freezing tolerance in the chloroplasts of nonacclimated plants [24]. In addition, COR47 is closely associated with frost tolerance and can act as an anti-dehydrating agent to prevent excessive dehydration damage to plant cells caused by low temperatures [25]. Accumulation of the dehydrin WCOR410 is associated with the capacity for high freezing tolerance in wheat (Triticum aestivum Linn.) [26]. Studies of the functions and regulated mechanisms of COR proteins, especially of the plasma membrane localization COR proteins, are helpful for understanding the relationship between the plasma membrane localization protein system and the tolerance to low-temperature stress.

To identify the gene function of COR413-PM1 under freezing stress, we obtained the Arabidopsis mutant cor413-pm1 and compared freezing stress tolerance between mutant and wild-type (WT) plants. Proteins are the major players in most cellular events, and unlike transcripts, proteins are the direct 
effectors of plant stress response. Thus, an investigation of changes in plant proteomes is highly important, and proteome analysis could help uncover additional novel proteins that respond to low temperatures [27]. Therefore, a proteomic analysis on seedling shoots of the mutant cor413-pm 1 and its WT was performed. In this study, 61 differentially abundant proteins (DAPs) associated with COR413-PM1 and 180 DAPs associated with freezing treatment were identified as being involved in physiological processes including the metabolisms of fatty acids, fructose and mannose, starch and sucrose, purine, amino sugars, and nucleotide sugars.

\section{Results}

\subsection{Gene Functions of COR413-PM1}

The expression patterns of COR413-PM1 under $4{ }^{\circ} \mathrm{C}$ in WT are shown in Supplementary Figure S1A. The expression of COR413-PM1 was upregulated; its maximum expression was 12.43-fold greater after $48 \mathrm{~h}$ of cold treatment. To identify the homozygous genotype of the transfer DNA (T-DNA) insertion mutant cor413-pm1, the DNA extractions of the mutant cor413-pm1 and WT were used as templates for amplification using the insertion site-specific primers of cor413-pm1 (T-DNA was inserted into the promoter region of COR413-PM1 gene shown in Figure 1B) and T-DNA border primer (LBb1.3) $[28,29]$. Primers used for mutant identification are listed in Supplementary Table S1. The fragment containing the T-DNA right border and part of the promoter of the COR413-PM1 gene could be amplified in the mutant cor413-pm1, whereas the fragment containing only the promoter of the COR413-PM1 gene could not be amplified in the mutant cor413-pm1 (Figure 1A). The result confirmed the homozygous genotype of the T-DNA insertion mutant cor413-pm1. In addition, the homozygous mutant, cor413-pm1, was confirmed through reverse transcription PCR (RT-PCR) and quantitative real-time PCR (qRT-PCR). Nothing was detected in the mutant cor413-pm1 by the qCOR413-PM1 primers. The relative expression level of COR413-PM1 in the cor413-pm1 was only $10.8 \%$ of WT (Supplementary Figure S1B). The PCR product of the mutant cor413-pm1 was sequenced and confirmed with the COR413-PM1 (AT2G15970) genome sequence from the Arabidopsis Information Resource (TAIR) database (Available online: http:/ / www.arabidopsis.org/). These results demonstrate that the T-DNA gene is inserted into the promoter region of COR413-PM1 gene in cor413-pm1 mutant, resulting in a significant decrease in COR413-PM1 gene expression. Then, the freezing stress tolerance of transgenic cor413-pm1 plants was investigated. The WT and cor413-pm1 mutant seedlings were exposed to $-8^{\circ} \mathrm{C}$ for $1 \mathrm{~h}$ in a refrigerator $\left(0.9 \times 0.7 \times 1.3 \mathrm{~m}^{3}\right)$. The phenotype of the mutant cor $413-p m 1$ seedlings was similar to that of the WT at normal temperature (Figure 1C), whereas the seedlings of cor413-pm1 were more sensitive to freezing stress than those of the WT at freezing temperature $\left(-8{ }^{\circ} \mathrm{C}\right)$. Leaves of the mutant cor $413-p m 1$ seedlings turned yellow and then died (Figure 1C), while the negative effects were not presented in the leaves of WT seedlings. The survival rate of the cor413-pm1 $(70.83 \%)$ was significantly lower than that of the WT $(81.25 \%)(p<0.05)$ (Figure 1D). Two physiological properties were investigated to evaluate tolerance to freezing stress: relative electrical conductivity and malondialdehyde (MDA) content. Relative electrical conductivity was used as an indicator of plasma membrane damage caused by freezing temperatures [30]. The results showed that relative electrical conductivity of all plants increased after exposure to the freezing treatment; relative electrical conductivity in cor413-pm1 was significantly higher than that in the WT $(p<0.05)$ (Figure 1E). Amounts of reactive oxygen species caused by the lipid peroxidation process increases under stress conditions, and MDA content is a typical indicator of membrane lipid peroxidation [31]. The MDA content of cor $413-p m 1$ was greater by $22.66 \%$ of that of the WT and reached $18.92 \mathrm{nmol} / \mathrm{g}$ after exposure to the freezing treatment $(p<0.05)$ (Figure 1F). These results showed that the membrane damage of cor413-pm1 mutant was more severe than WT at low temperatures and tolerance to low-temperature stress was significantly lower than that of WT. 
A

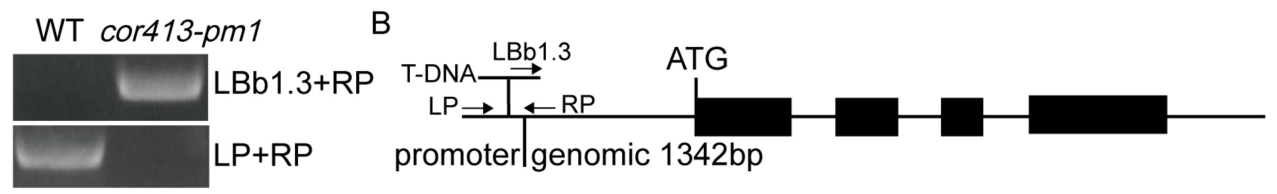

C

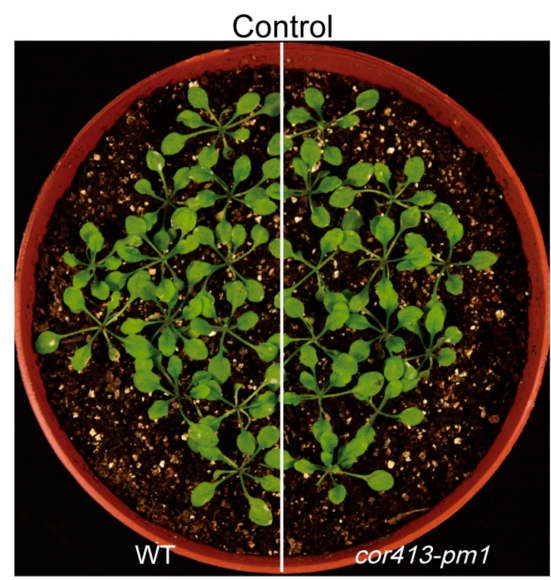

$\mathrm{D}$

$$
\text { के }
$$

E
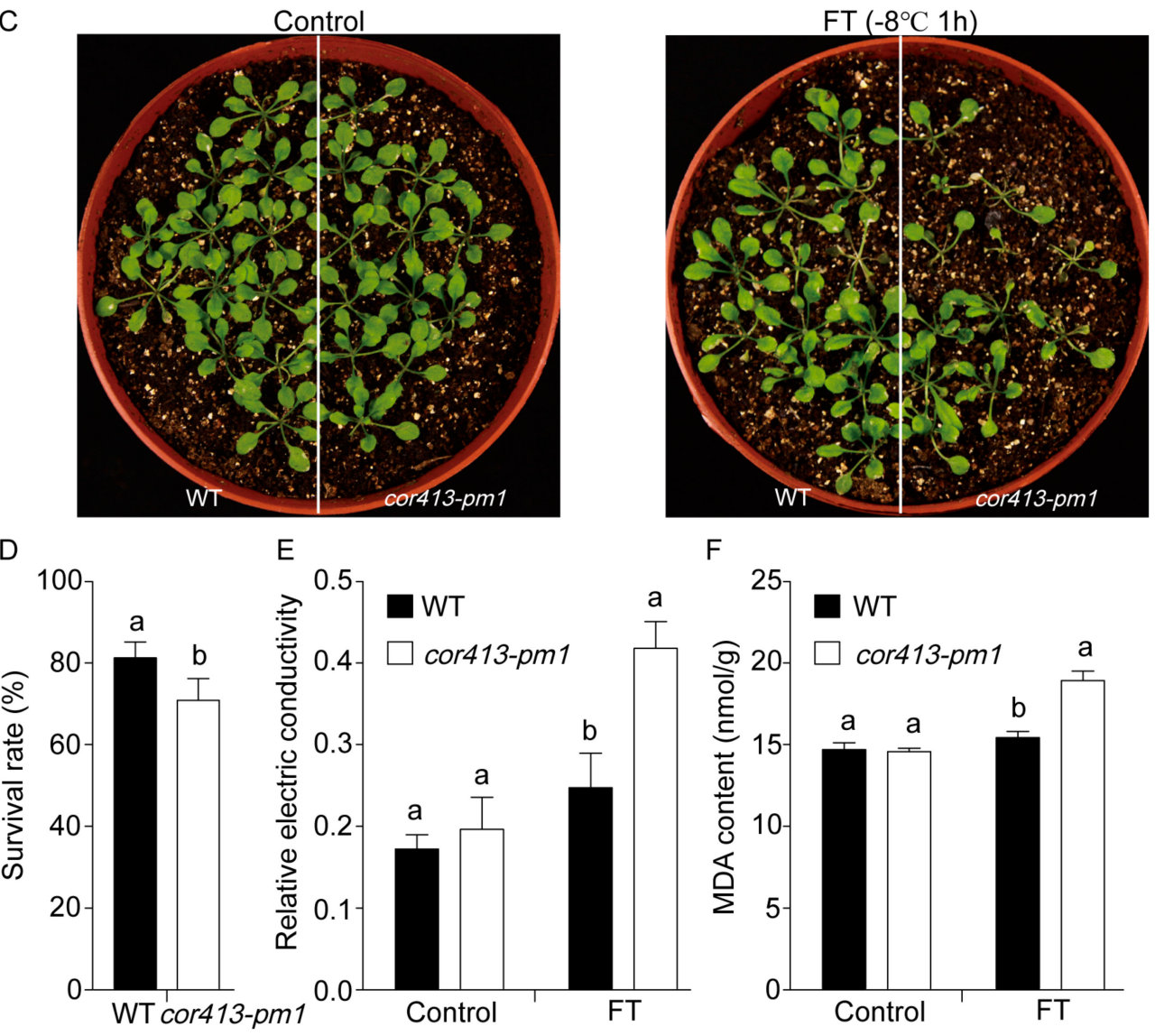

$\mathrm{F}$

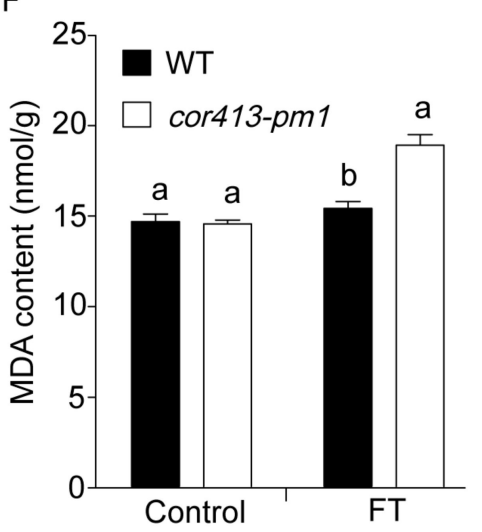

Figure 1. Identification of the mutant cor413-pm1 and growth phenotypes of the cor413-pm1 and wild-type (WT) exposed to the freezing treatment (FT). (A) Identification of the homozygous mutant cor413-pm1. (B) Insertion site of transfer DNA (T-DNA) in the promoter region of the mutant cor413-pm1. The black box represents the exons. (C) Freezing stress tolerance assay of cor413-pm1 and WT. (D) Comparison of survival rates between cor413-pm1 and WT after exposure to the freezing treatment. Error bars indicate standard deviation (SD) $(n=4)($ E) Relative electrical conductivity and (F) malondialdehyde (MDA) content of cor413-pm1 compared with those of the WT. Error bars indicate the standard error of the mean (SEM) $(n=3)$. Different letters in $(\mathbf{D}-\mathbf{F})$ indicate significant differences between WT and cor413-pm1 at $p<0.05$.

\subsection{Identification of Differentially Abundant Proteins (DAPs) in Seedling Shoots of cor413-pm1 and WT}

Fourteen-day-old seedlings grown in soil were sampled for proteomic analysis. The treatment condition of freezing stress was placing pots with seedlings at $-8{ }^{\circ} \mathrm{C}$ for $1 \mathrm{~h}$. Total proteins in the seedling shoots were extracted from cor413-pm1 and WT plants exposed to control and freezing treatment conditions, with three replicates for each of the four plant-treatment combinations. A label-free mass-spectrometry-based proteomics approach was used to explore the DAPs between treatment groups. The separation of chromatographic peaks was shown in Total Ions Chromatograms (TIC) (Supplementary Figure S2). A Venn diagram shows the distribution of a total of 4143 qualitative proteins in cor413-pm1 and WT of the control and freezing treatment groups (Figure 2A). The types of proteins identified in the four groups were highly dependent on plant type and treatment, but about $49 \%$ of the total identified proteins were simultaneously detected in all groups. Figure $2 \mathrm{~A}$ also showed 
that a total of 2743 common proteins were identified both in control condition cultured cor413-pm1 and WT, while 2253 common proteins were identified in both freezing-treated cor413-pm1 and WT. More differences were observed between cor413-pm1 and WT after freezing treatment (Figure 2A). A Pearson correlation analysis of four groups indicated that the correlation coefficients of quantitative proteins among the four treatment groups were above 0.9 (Figure 2B). The correlation coefficient between cor413-pm1 and WT was 0.997 under normal conditions, whereas the correlation coefficient between cor413-pm1 and WT was lower (0.976) after exposure to the freezing treatment (Figure 2B). These data suggest that the protein expression profile of the mutant cor413-pm1 was similar to that of the WT under normal conditions, whereas the protein expression profiles differed after exposure to the freezing treatment. In addition, the distribution of numbers of different proteins observed in a log scale of signal intensities (which represents the abundances of each protein) mainly concentrated in the $10^{7}-10^{8}$ range in all four treatment combinations (Figure 2C). Further, when exposed to the freezing treatment, the number of low abundance $\left(10^{6}-10^{7}\right)$ proteins in cor413-pm1 mutant (FT-cor413-pm1) was more than WT (FT-WT) (Figure 2C).

A

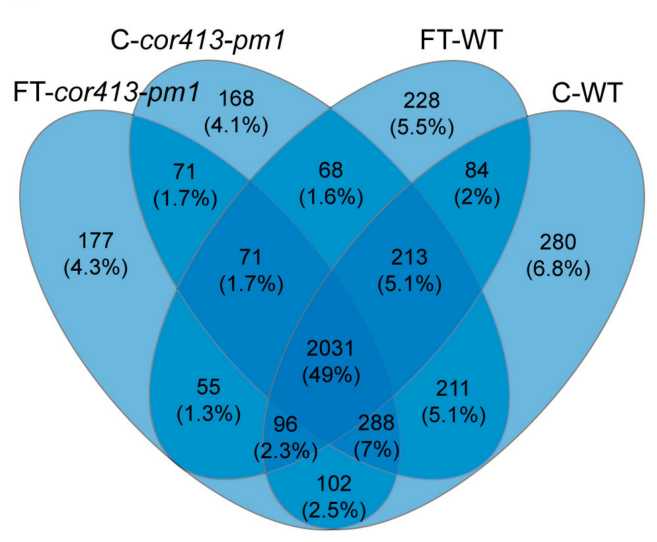

C

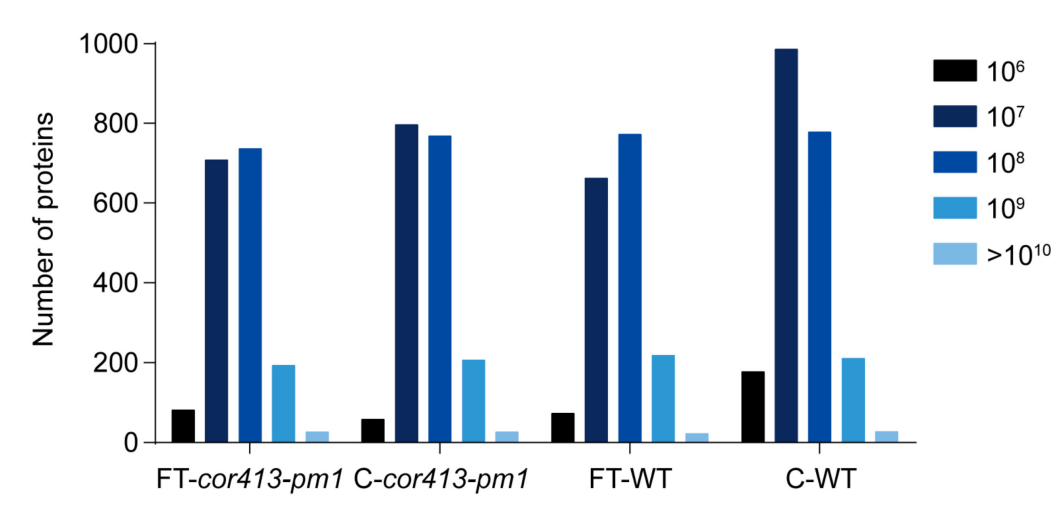

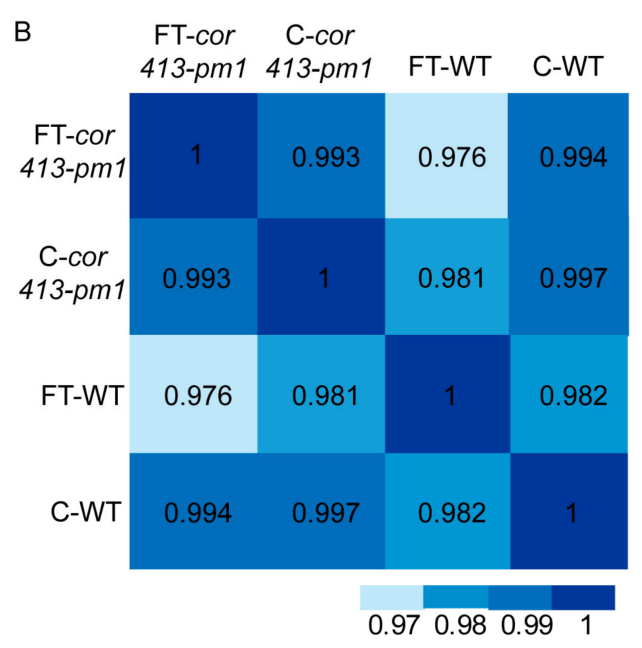

Figure 2. Analysis of qualitative and quantitative identification of proteins of cor413-pm1 and WT seedling shoots. (A) Venn diagram of qualitatively identified proteins in cor413-pm1 and WT when plants were exposed or nonexposed to a freezing treatment. C-cor413-pm1: cor413-pm1 seedling shoots not exposed to freezing temperature; FT-cor413-pm1: cor413-pm1 seedling shoots exposed to freezing temperature; C-WT: WT seedling shoots not exposed to freezing temperature; FT-WT: WT seedling shoots exposed to freezing temperature. The percentage in parentheses show the proportion of this protein group in a total of 4143 proteins. (B) Pearson correlation analysis of the four plant-treatment combinations. Abscissa and ordinate indicate the names of treatment groups. Shades of blue color represent correlation coefficients. (C) Distribution of numbers of proteins observed along a range of signal intensities in each treatment group. 
Among all identified proteins, a total of 3139 proteins were accurately quantitated. For screening of DAPs, the signal intensity of a protein in a given sample was compared to the signal intensity of the control. When the ratio was greater than twofold or less than half, the protein was considered to be an upregulated or downregulated DAP, respectively. The fold changes and $p$-values of DAPs are listed in Supplementary Table S1. The volcano plot exhibits high similarity between cor413-pm1 and WT without freezing treatment (Figure 3A). On the other hand, there was a large difference in amounts of both high and low abundance proteins between cor413-pm1 and WT after exposure to the freezing treatment compared with that under normal conditions (Figure 3B). It is important to note that many downregulated and upregulated DAPs were also identified in freezing treated and nonfreezing treated cor413-pm1 or WT (Figure 3C,D).

A

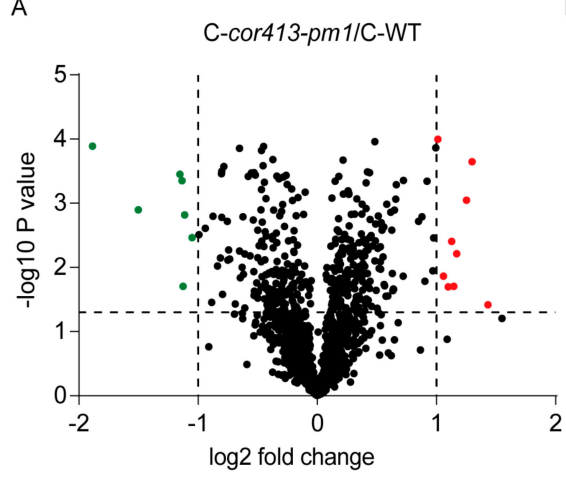

C

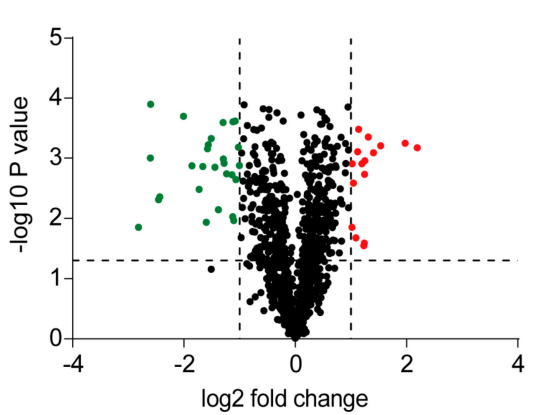

B

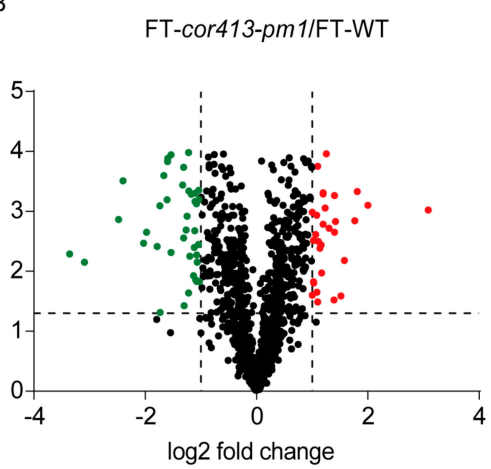

D

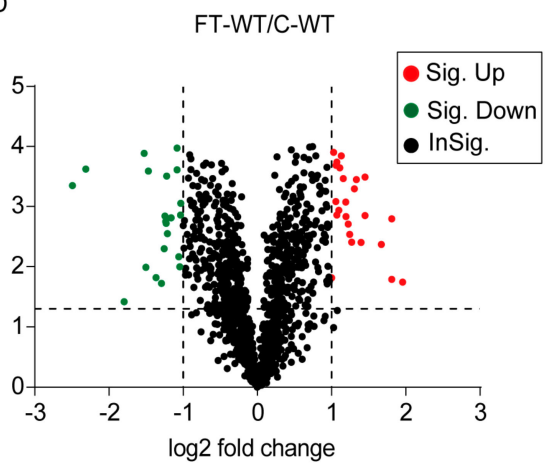

Figure 3. Volcano plots depicting the variance in expression between cor413-pm1 and WT samples. The significantly changed proteins in (A) C-cor413-pm1 and C-WT, (B) FT-cor413-pm1 and FT-WT, (C) FT-cor413-pm1 and C-cor413-pm1, and (D) FT-WT and C-WT. Dotted vertical lines indicate standards deviation from the mean fold change and $p$-value. Points plotted in the upper right and upper left corners have the highest precision and greatest absolute fold change. Red: significantly upregulated DAPs; green: significantly downregulated DAPs.

The numbers of DAPs detected in the comparison of samples are shown in Table 1. A total of 1125, 923, 946, and 1346 DAPs (upregulated plus downregulated DAPs) was detected in the comparison of FT-cor413-pm1 vs. FT-WT, C-cor413-pm1 vs. C-WT, FT-cor413-pm1 vs. C-cor413-pm1, and FT-WT vs. C-WT, respectively (Table 1). The number of upregulated proteins was similar to downregulated proteins in FT-cor413-pm1 vs. FT-WT, but the number of upregulated proteins was lower than that of the downregulated proteins in C-cor413-pm1 vs. C-WT (Table 1). The ratio of upregulated to downregulated proteins in FT-cor413-pm1 vs. C-cor413-pm1 (1:1.3) was higher than FT-WT vs. C-WT (1:1.9) (Table 1). The number of upregulated and downregulated proteins in cor413-pm1 across treatments (e plus $g$ in Table 1, 946 proteins) was lower than the number in the WT (f plus $\mathrm{h}$ in Table 1, 1346), which demonstrated that the response to freezing treatment in cor413-pm1 was weaker than in WT. 
Table 1. Differentially abundant proteins (DAPs) detected in comparison of samples.

\begin{tabular}{ccccc}
\hline Treatment Groups & $\begin{array}{c}\text { Upregulated } \\
\text { Proteins }\end{array}$ & $\begin{array}{c}\text { Downregulated } \\
\text { Proteins }\end{array}$ & $\begin{array}{c}\text { Unchanged } \\
\text { Proteins }\end{array}$ & $\begin{array}{c}\text { Total } \\
\text { Proteins }\end{array}$ \\
\hline FT-cor $413-p m 1^{1}$ vs. FT-WT ${ }^{2}$ & $552(\mathrm{a})$ & $573(\mathrm{c})$ & 1125 & 2250 \\
C-cor $413-p m 1^{3}$ vs. C-WT & $298(\mathrm{~b})$ & $625(\mathrm{~d})$ & 1537 & 2460 \\
FT-cor413-pm1 vs. C-cor413-pm1 & $407(\mathrm{e})$ & $539(\mathrm{~g})$ & 1288 & 2234 \\
FT-WT vs. C-WT & $458(\mathrm{f})$ & $888(\mathrm{~h})$ & 1243 & 2589 \\
\hline
\end{tabular}

${ }^{1}$ cor413-pm1 seedling shoots treated with freezing temperature; ${ }^{2}$ WT seedling shoots treated with freezing temperature; ${ }^{3}$ cor413-pm1 seedling shoots at control temperature; ${ }^{4}$ WT seedling shoots at control temperature; a: the upregulated proteins of FT-cor413-pm1 vs. FT-WT; b: the upregulated proteins of C-cor413-pm1 vs. C-WT; c: the downregulated proteins of FT-cor413-pm1 vs. FT-WT; d: the downregulated proteins of C-cor413-pm1 vs. C-WT; e: the upregulated proteins of FT-cor413-pm1 vs. C-cor413-pm1; f: the upregulated proteins of FT-WT vs. C-WT; g: the downregulated proteins of FT-cor413-pm1 vs. C-cor413-pm1; h: the downregulated proteins of FT-WT vs. C-WT.

We found 61 (1.94\%) DAPs associated with COR413-PM1. Among them, a total of 27 upregulated proteins occurred in both FT-cor413-pm1 vs. FT-WT group (a) and C-cor413-pm1 vs. C-WT group (b) (Table 1, Figure 4A). A total of 34 downregulated proteins were found in both the FT-cor413-pm1 vs. FT-WT group (c) and C-cor413-pm1 vs. C-WT group (d) (Table 1; Figure 4B). The 180 (5.73\%) DAPs associated with the freezing treatment in both the mutant cor413-pm1 and WT were selected for further analysis. Venn diagrams illustrate the shared 30 DAPs of upregulated proteins (Figure 4C) and shared 150 DAPs of downregulated proteins (Figure 4D) associated with freezing treatment. The details of the upregulated and downregulated proteins are listed in Supplementary Table S2.

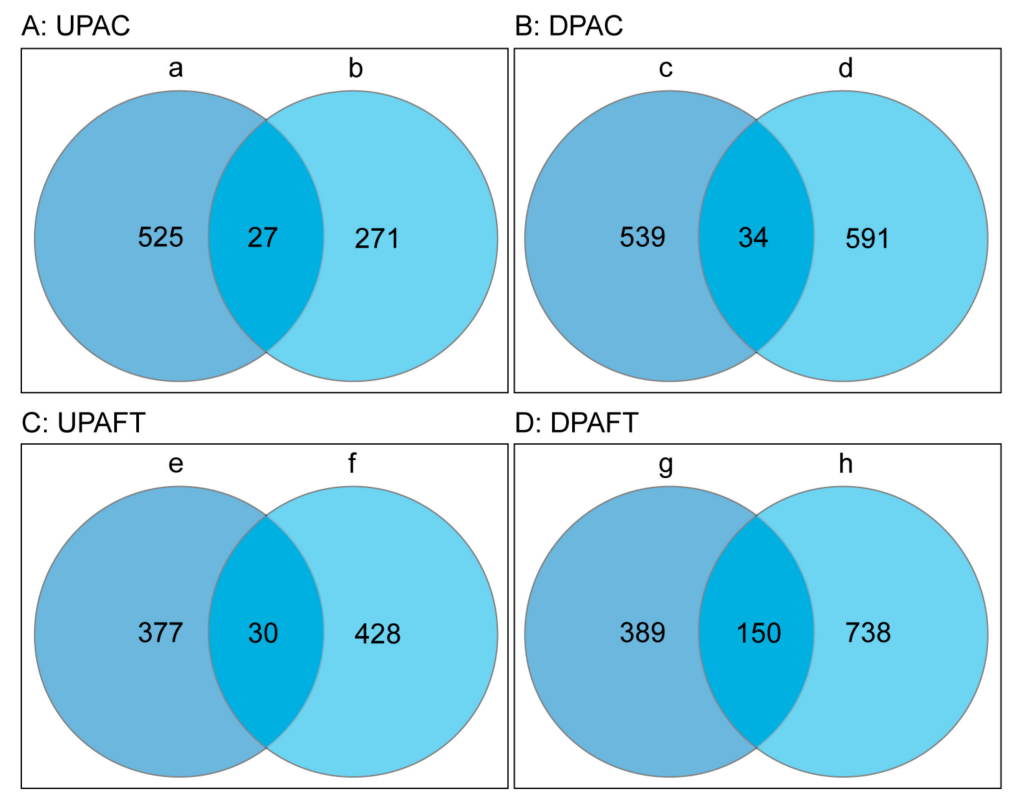

Figure 4. Venn diagrams of DAPs. (A) Upregulated proteins and (B) downregulated proteins in cor413-pm1 compared with WT at both freezing and normal temperatures. (C) Upregulated proteins and (D) downregulated proteins of the mutant cor413-pm1 and WT after exposure to freezing temperature. The total numbers of proteins are shown for each group. a: the upregulated proteins of FT-cor413-pm1 vs. FT-WT; b: the upregulated proteins of C-cor413-pm1 vs. C-WT; c: the downregulated proteins of FT-cor413-pm1 vs. FT-WT; d: the downregulated proteins of C-cor413-pm1 vs. C-WT; e: the upregulated proteins of FT-cor413-pm1 vs. C-cor413-pm1; f: the upregulated proteins of FT-WT vs. C-WT; g: the downregulated proteins of FT-cor413-pm1 vs. C-cor413-pm1; h: the downregulated proteins of FT-WT vs. C-WT. UPAC: upregulated proteins associated with COR413-PM1, DPAC: downregulated proteins associated with COR413-PM1, UPAFT: upregulated proteins associated with freezing treatment, DPAFT: downregulated proteins associated with freezing treatment. 
In total, intensities of 61 DAPs were larger different between cor413-pm1 and WT (Figure 5) and 180 DAPs were significantly larger different between the freezing treatment and normal treatment (Figure 6), which suggests that 61 DAPs and 180 DAPs were part of a specific response to COR413-PM1 and the freezing treatment, respectively.

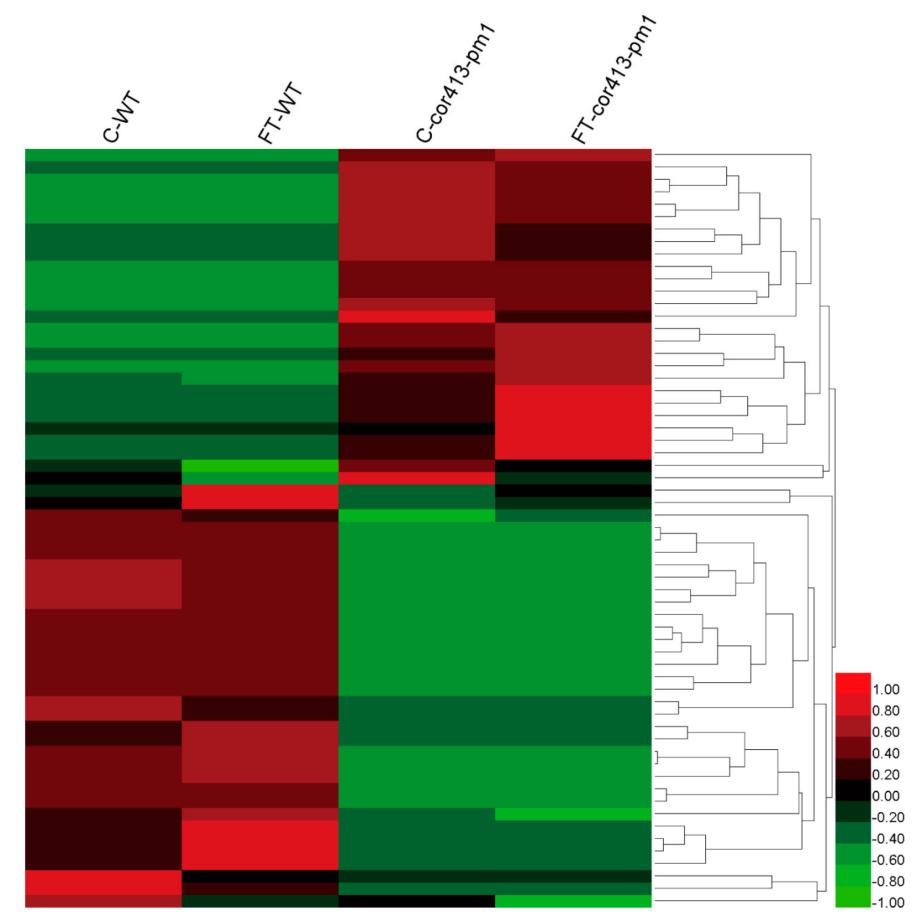

Figure 5. Heatmap based on intensities of the 61 DAPs associated with COR413-PM1. Red color indicates the higher protein intensities which set " 1 ", black color indicates " 0 ", and green color indicates lower intensities which set "-1" of C-WT, FT-WT, C-cor413-pm1, and FT-cor413-pm1. Lines show the clustering of the DAPs in the heatmap.

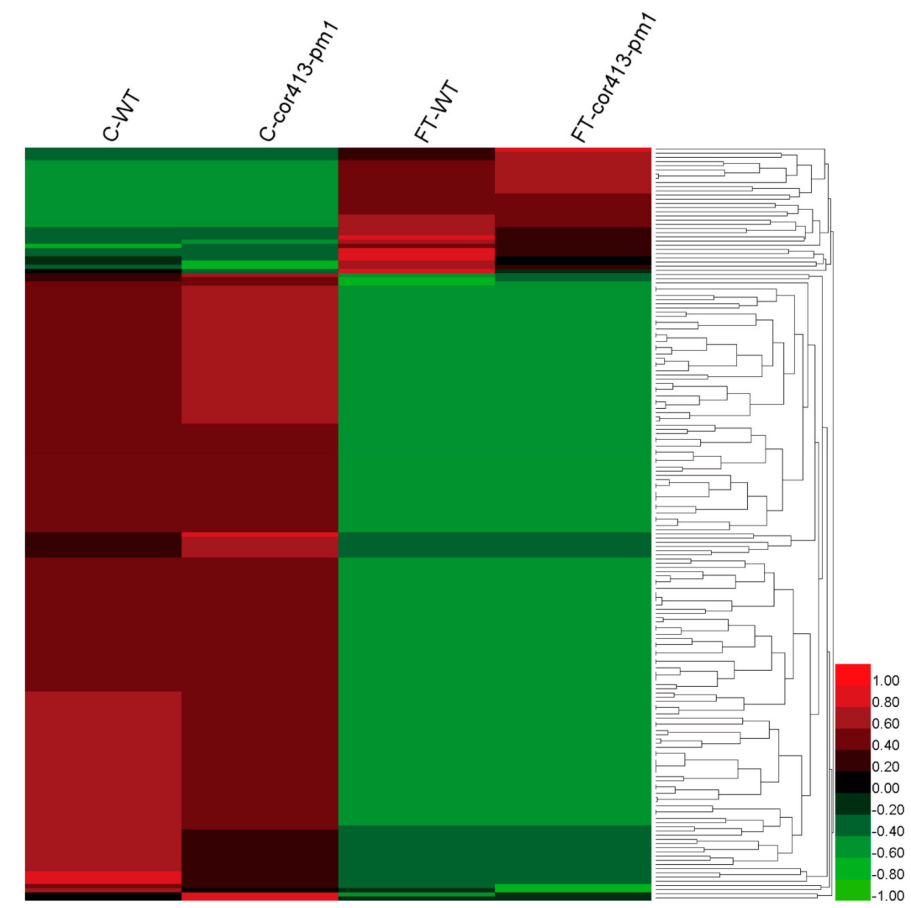

Figure 6. Heatmap based on intensities of the 180 DAPs associated with freezing treatment. 


\subsection{Categorization of DAPs in Seedling Shoots}

To gain insight into the functional categories of DAPs that were altered between cor413-pm1 and WT seedling shoots, Gene Ontology (GO) categories were assigned based on the Gene Ontology database (Available online: http:/ / www.geneontology.org/). The distribution charts of the GO terms and pathway enrichment according to the corresponding classifications of biological process (BP), cellular component (CC), and molecular function (MF) are shown in Figures 7 and 8. These figures give an overview of the GO analysis with up to 10 significantly enriched terms in the $\mathrm{BP}, \mathrm{CC}$, and $\mathrm{MF}$ categories. The majority of the 27 upregulated DAPs found in cor413-pm1 seedling shoots appeared to be related to 447 biological changes, with 105 terms significantly enriched in BP. A total of $115 \mathrm{GO}$ terms were enriched in CC, of which 35 terms reached statistical significance. Thirty-nine terms were significantly enriched in MF (Figure 7A). The majority of the 34 downregulated DAPs found in cor413-pm 1 seedling shoots appeared to be related to $580 \mathrm{BP}$ terms, of which 157 terms were significantly enriched. A total of 75 terms were enriched in $\mathrm{CC}$, of which 30 terms were significantly enriched. A total of 38 terms were significantly enriched in MF in this dataset (Figure 7B). The top 10 terms significantly enriched in the three categories are shown in Figure 7. The first three BP terms of the 27 upregulated proteins were sepal vascular tissue pattern formation, positive regulation of endopeptidase activity, and response to growth hormone (Figure 7A). The 34 downregulated proteins' first three BP terms were protein peptidyl-prolyl isomerization, peptidyl-proline modification, and ncRNA metabolic process (Figure 7B). The first three CC terms of the 27 upregulated proteins were cytoplasm, cytoplasmic part, and cytosol (Figure 7A). The 34 downregulated proteins' first three CC terms were mainly related to cytoplasmic part, cytoplasm, and cytosol (Figure 7B). The first three MF terms of the 27 upregulated proteins were amino-terminal vacuolar sorting propeptide binding, endopeptidase activator activity, and phosphatidylinositol-4-phosphate binding (Figure 7A). The 34 downregulated proteins' first three MF terms were mainly related to peptidyl-prolyl cis-trans isomerase activity, cis-trans isomerase activity, and oxidoreductase activity (Figure 7B).

The majority of the 30 upregulated DAPs in the seedling shoots that associated with freezing treatment appeared to be related to 429 biological changes, with 92 terms significantly enriched in BP. A total of 95 GO terms were enriched in CC, of which 29 terms reached statistical significance. Forty-three terms were significantly enriched in MF (Figure 8A). The majority of the 150 downregulated DAPs associated with freezing treatment appeared to be related to $1258 \mathrm{BP}$ terms, of which 570 terms were significantly enriched. A total of 195 terms were enriched in CC, of which 100 terms were significantly enriched. One hundred and forty terms were significantly enriched in MF (Figure 8B). The top 10 terms significantly enriched in the three categories are shown in Figure 8 . The first three BP terms of the 30 upregulated proteins were carbohydrate biosynthetic process, single-organism carbohydrate metabolic process, and guard cell morphogenesis (Figure 8A). The 150 downregulated proteins' first three BP terms were mainly related to small molecule metabolic, single-organism biosynthetic, and oxoacid metabolic processes (Figure $8 \mathrm{~B}$ ). The first three CC terms of the 30 upregulated proteins were organelle envelope, envelope, and plastid (Figure 8A). The 150 downregulated proteins' first three CC terms were same as the 34 downregulated proteins (Figure 8B). The first three MF terms of the 30 upregulated proteins were ferredoxin: thioredoxin reductase activity, 4 iron and 4 sulfur cluster binding, and ADP-ribose pyrophosphohydrolase activity (Figure 8A). The 150 downregulated proteins' first three MF terms were mainly related to oxidoreductase activity, antioxidant activity, and 3 iron, 4 sulfur cluster binding (Figure 8B). 


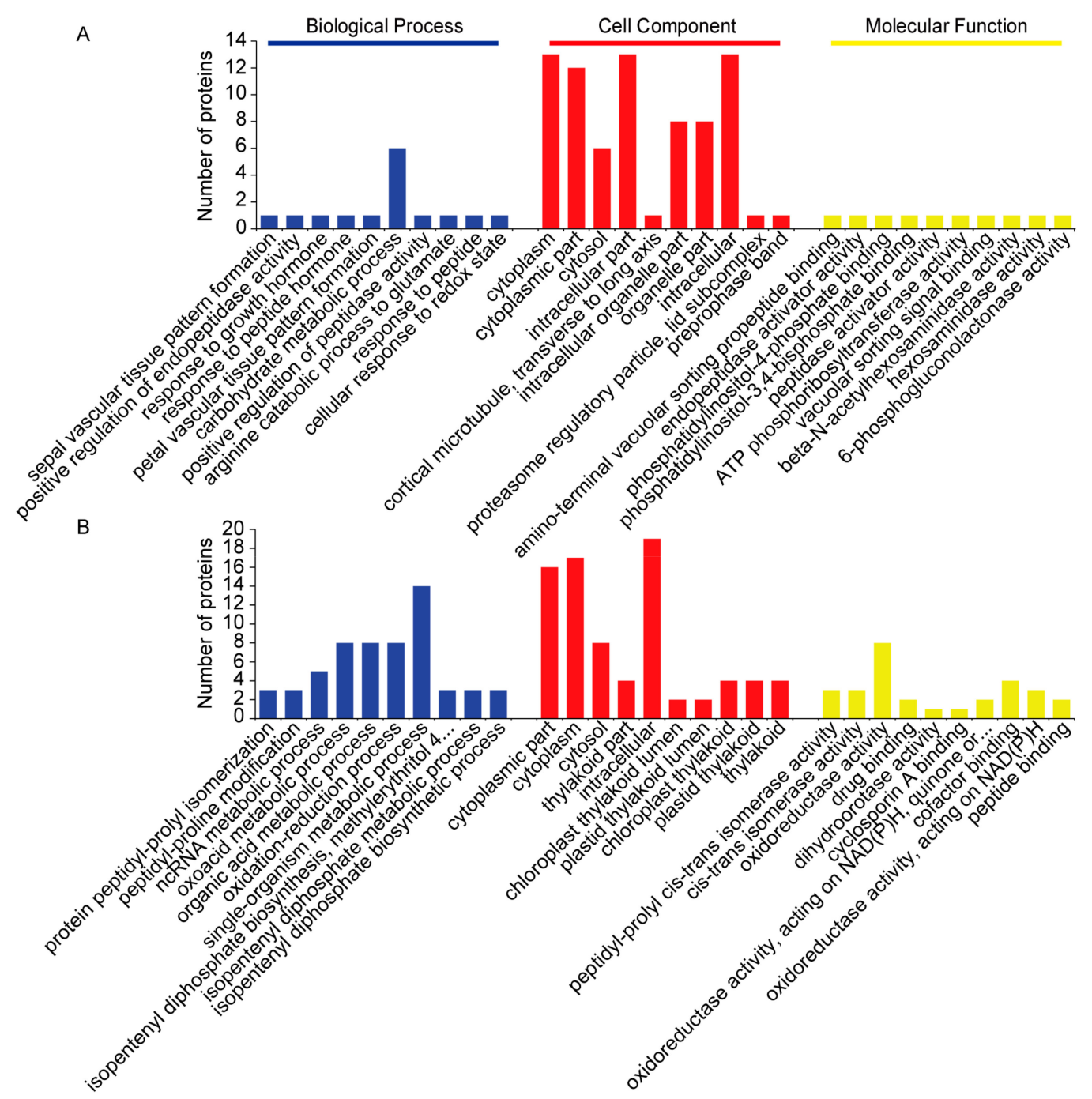

Figure 7. GO analysis of the DAPs associated with cold-regulated multispanning transmembrane gene COR413-PM1. The top 10 terms significantly enriched in the three categories (biological process (BP), cellular component (CC), and molecular function (MF)) of the GO terms analysis are displayed. (A) GO analysis of 27 upregulated DAPs associated with COR413-PM1 in seedling shoots; (B) GO analysis of 34 downregulated DAPs associated with COR413-PM1 in seedling shoots. Terms in each category are arranged, from left to right, from the highest to lowest $p$-values $(p<0.05)$. The numbers of proteins are shown on the y-axis.

Analysis results from using the Kyoto Encyclopedia of Genes and Genomes (KEGG) Pathway database (Available online: http:/ / www.kegg.jp/) indicated that the 27 upregulated DAPs found in cor413-pm1 seedling shoots mapped to 21 KEGG pathways. These most significantly enriched KEGG pathways were involved in glycosphingolipid biosynthesis-ganglio series (ath00604, $p=8.30 \times 10^{-3}$ ), glycosaminoglycan degradation (ath00531, $p=1.16 \times 10^{-2}$ ), glycosphingolipid biosynthesis-globo series (ath00603, $p=1.49 \times 10^{-2}$ ), histidine metabolism (ath00340, $p=2.96 \times 10^{-2}$ ), other glycan degradation (ath00511, $p=2.96 \times 10^{-2}$ ), and metabolic pathways (ath01100, $p=4.76 \times 10^{-2}$ ) (Figure 9A). The KEGG pathways of the 34 significantly downregulated DAPs in cor413-pm1 functioned in aminoacyl-tRNA biosynthesis (ath00970, $p=1.83 \times 10^{-2}$ ), selenocompound metabolism (ath00450, $p=3.32 \times 10^{-2}$ ), and glucosinolate biosynthesis (ath00966, $p=3.51 \times 10^{-2}$ ) (Figure 9B). Panels of upregulated and downregulated DAPs associated with COR413-PM1 of KEGG pathways are shown in Supplementary Figure S3. 


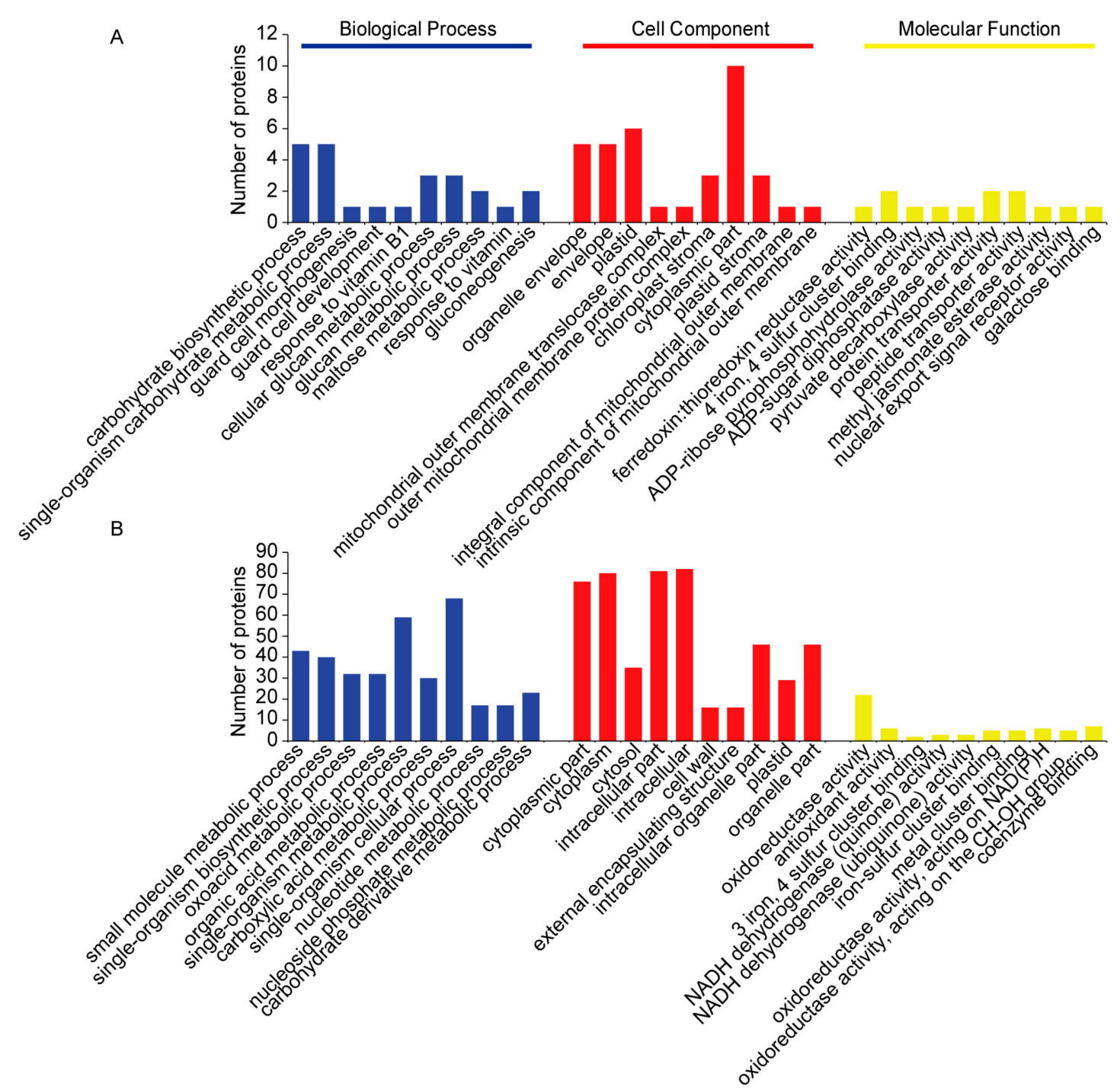

Figure 8. GO analysis of the DAPs associated with freezing treatment. The top 10 terms significantly enriched in the three categories (BP, CC, and MF) of the GO terms analysis are displayed. (A) GO analysis of 30 upregulated DAPs associated with freezing treatment; (B) GO analysis of 150 downregulated DAPs associated with freezing treatment.

Moreover, the analysis with the KEGG Pathway database indicated that the 30 upregulated DAPs associated with freezing treatment of the seedling shoots mapped to 11 KEGG pathways. The most significantly enriched KEGG pathways were involved in indole alkaloid biosynthesis (ath00901, $p=7.47 \times 10^{-3}$ ) and thiamine metabolism (ath00730, $p=1.37 \times 10^{-2}$ ) (Figure 9C). The KEGG pathways of the 150 significantly downregulated DAPs were associated with freezing treatment and nitrogen metabolism (ath00910, $p=7.71 \times 10^{-3}$ ), oxidative phosphorylation (ath00190, $p=2.00 \times 10^{-2}$ ), fatty acid metabolism (ath01212, $p=3.04 \times 10^{-2}$ ), AGE-RAGE signaling pathway in diabetic complications (ath04933, $p=3.22 \times 10^{-2}$ ), 2-oxocarboxylic acid metabolism (ath01210, $p=3.51 \times 10^{-2}$ ), biosynthesis of secondary metabolites (ath01110, $p=4.14 \times 10^{-2}$ ), and amino sugar and nucleotide sugar metabolism (ath00520, $p=4.19 \times 10^{-2}$ ) (Figure 9D). Panels of upregulated and downregulated DAPs associated with freezing treatment of KEGG pathways are shown in Supplementary Figure S4. The main proteins of the DAPs associated with COR413-PM1 and freezing treatment are shown in Supplementary Table S2. 
A

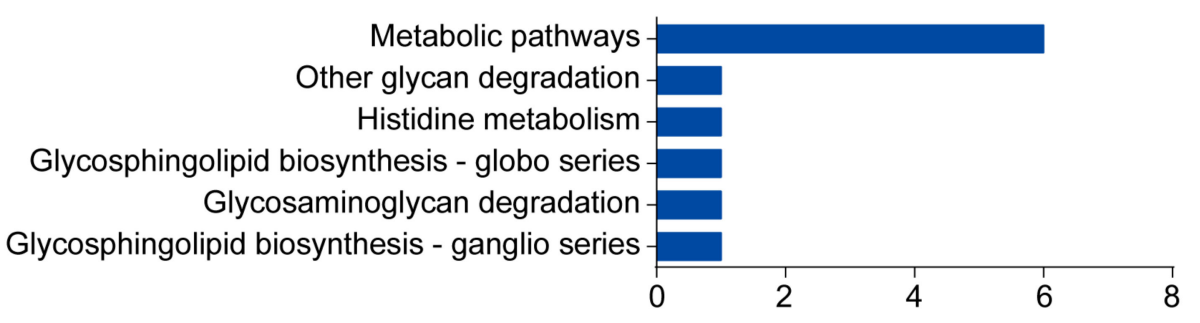

B

Glucosinolate biosynthesis Selenocompound metabolism Aminoacyl-tRNA biosynthesis

C

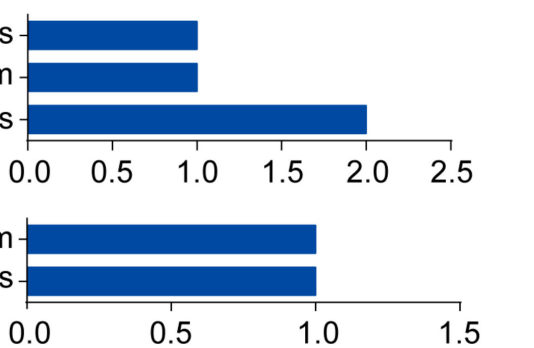

D

Amino sugar and nucleotide sugar metabolism Biosynthesis of secondary metabolites 2-Oxocarboxylic acid metabolism AGE-RAGE signaling pathway in diabetic complications Fatty acid metabolism Oxidative phosphorylation Nitrogen metabolism

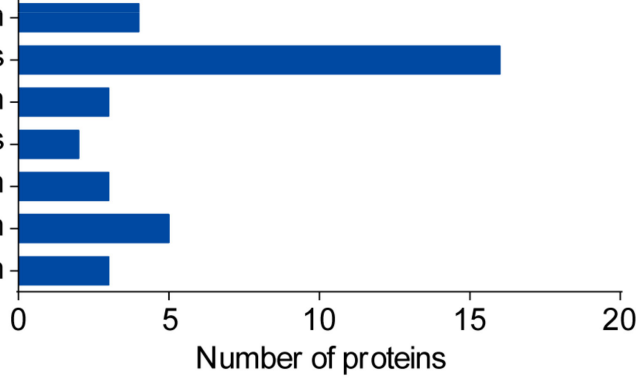

Figure 9. KEGG pathway enrichment of the DAPs associated with cold-regulated multispanning transmembrane gene COR413-PM1 and freezing treatment in seedling shoot material. (A) KEGG pathway enrichment of 27 upregulated DAPs associated with COR413-PM1 gene; (B) KEGG pathway enrichment of 34 downregulated DAPs associated with COR413-PM1 gene; (C) KEGG pathway enrichment of 30 upregulated DAPs associated with freezing treatment; (D) KEGG pathway enrichment of 150 downregulated DAPs associated with freezing treatment.

\section{4. $q R T-P C R$ Analysis}

Among DAPs, we selected eight proteins that have been reported in relation to low-temperature stress, and qRT-PCR validation of these proteins was completed. Among them, it was demonstrated in this study that fatty acid biosynthesis 1 (FAB1)/beta-ketoacyl-ACP synthetase 2 (KAS2) (AT1G74960), GLN phosphoribosyl pyrophosphate amidotransferase 2 (ASE2) (AT4G34740), and SM-like protein 4 (LSM4) (AT5G27720) were associated with the freezing treatment. The other five proteins are vitamin C defective 1 (VTC1)/cytokinesis defective 1 (CYT1)/GDP-mannose pyrophosphorylase (GMP1) (AT2G39770), trehalose-6-phosphatase synthase S7 (TPSA/TPS7) (AT1G06410), fructokinase 3 (FRK3/FRK6) (AT1G66430), sucrose phosphate synthase A1 (SPSA1) (AT5G20280), and pyrimidine 1 (PYD1) (AT3G17810).

Expression levels of most of the eight proteins were downregulated in cor413-pm1 when compared to those of WT, whether under normal or freezing temperatures. The expression levels of FAB1, ASE2, FRK3, SPSA1, and PYD1 were consistent with protein intensities (Figure 10A,B,D,E,H). The expression levels of LSM4, CYT1, and TPS7 were not consistent with their protein intensities (Figure 10C,F,G). Previous studies have shown that gene expression level might not be consistent with protein level because of post-translational regulation mechanisms [32-34]. The intensities of FAB1, ASE2, LSM4, CYT1, and TPS7 in freezing treatment were not consistently detectable in both plant lines (Figure 10A-C,F,G) and those proteins might be present but intensities were too weak to detect using the proteomic method. 
A

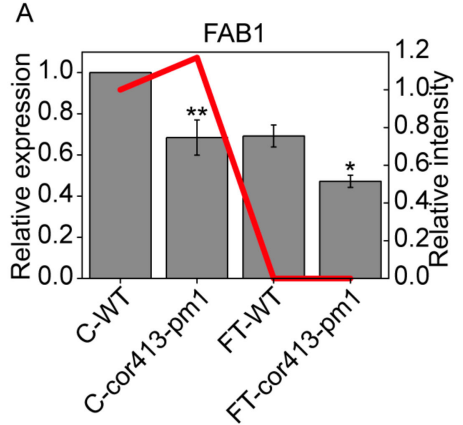

D

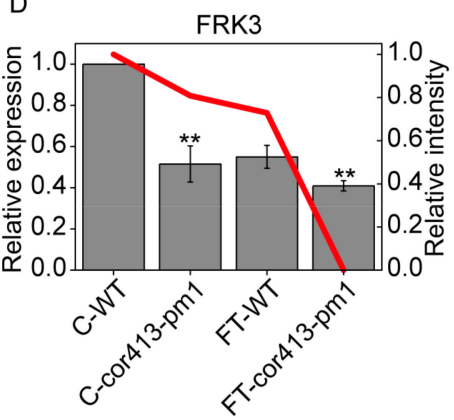

G

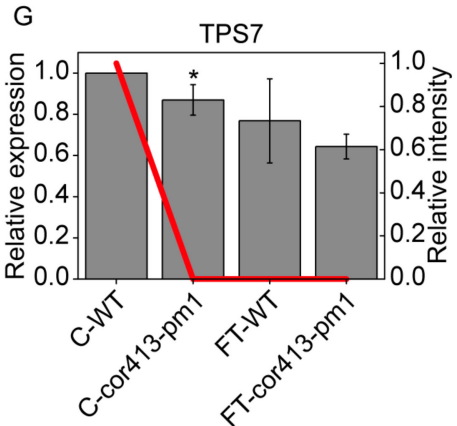

B

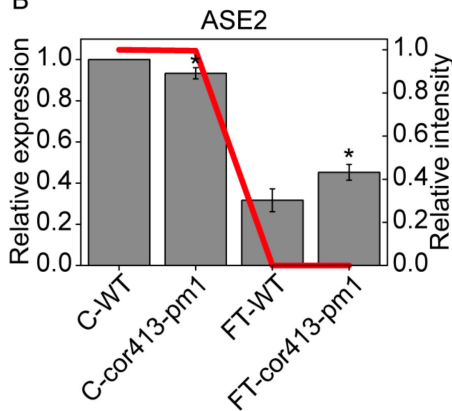

$\mathrm{E}$

$E$

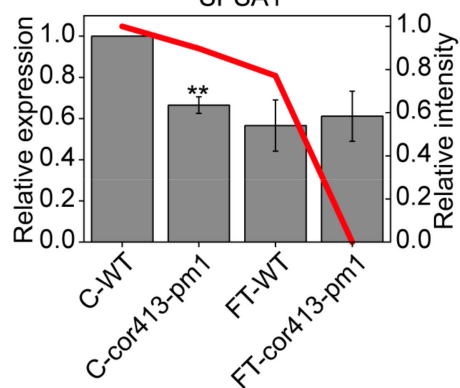

$\mathrm{H}$

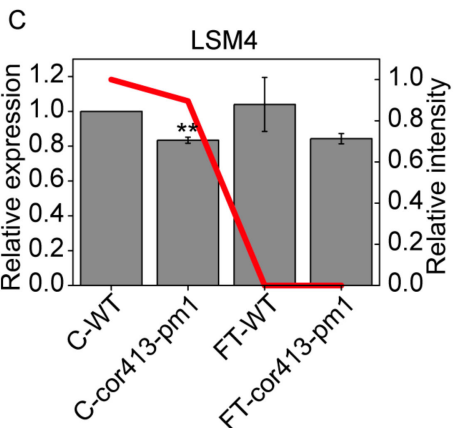

$\mathrm{F}$

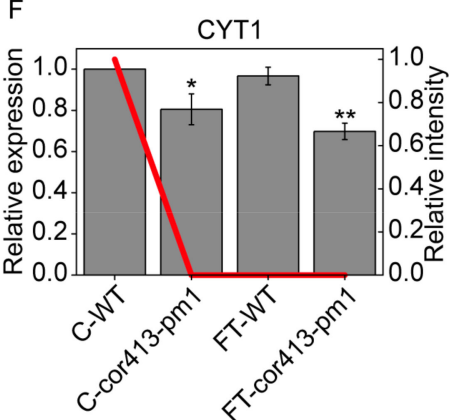

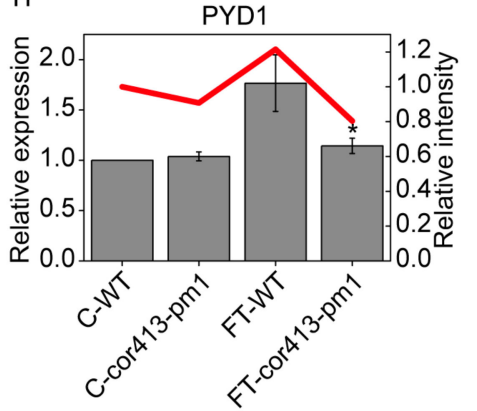

Figure 10. Proteomics targeting intensities (line chart) and quantitative real-time PCR (qRT-PCR) (histogram) of candidate DAPs. Expression levels of (A) fatty acid biosynthesis 1 (FAB1)/beta-ketoacyl-acp synthetase 2 (KAS2), (B) GLN phosphoribosyl pyrophosphate amidotransferase 2 (ASE2), (C) SM-like protein 4 (LSM4), (D) fructokinase 3 (FRK3/FRK6), (E) sucrose phosphate synthase A1 (SPSA1), (F) vitamin C defective 1 (VTC1)/cytokinesis defective 1 (CYT1), (G) trehalose-6-phosphatase synthase S7 (TPSA/TPS7), and (H) pyrimidine 1 (PYD1) in the seedling shoots of WT and cor413-pm1. Red lines are proteomics targeting intensities. Data shown are means $\pm \operatorname{SD}(n=4)$. The analysis for significant differences is the same treatment condition group. ${ }^{*} p<0.05,{ }^{* *} p<0.01$ (Student's $t$-test).

\subsection{Protein-Protein Interaction Analysis of DAPS}

To predict the relationships among the selected eight DAPs in the different KEGG pathways, protein-protein interaction (PPI) networks were generated by the webtool Search Tool for the Retrieval of Interacting Genes (STRING) [35] and TAIR10. Several KEGG pathways were enriched in the PPI network, including the metabolisms of amino and nucleotide sugars, fructose and mannose, starch and sucrose, and purine. We ultimately obtained 29 related proteins participating in PPI networks (Figure 11). Among pathways, we found that, confirmed using qRT-PCR, four DAPs, including FAB1/KAS2, FRK3/FRK6 (AT1G66430), SPSA1/SPS1, and ASE2, were involved in metabolic processes of fatty acids, sugars, and purine, which suggests that COR413-PM1 mainly regulated freezing tolerance through affecting these metabolism processes in plants. 


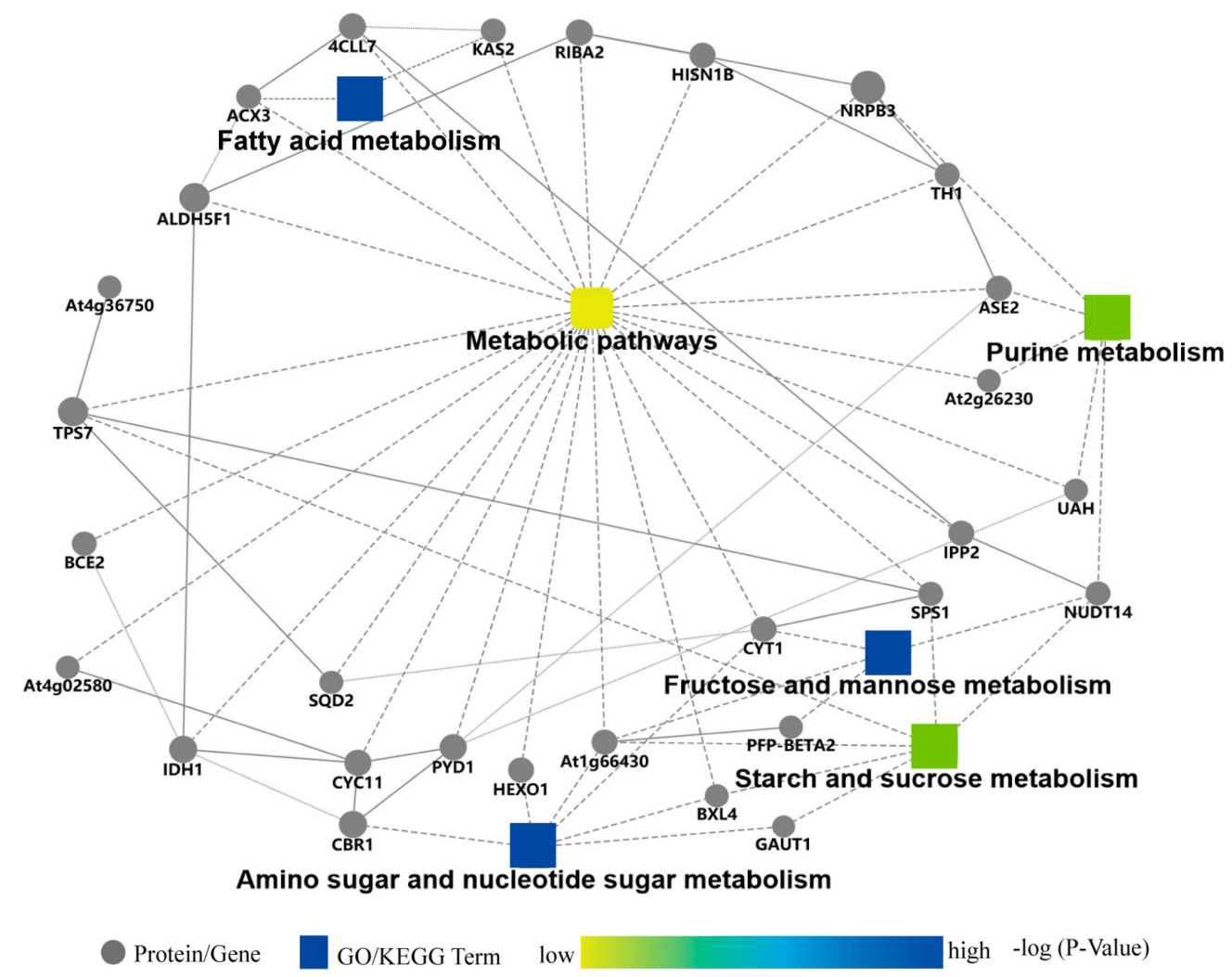

Figure 11. The protein-protein interaction (PPI) network of the main DAPs involved in metabolic pathways. FAB1 (KAS2) enriches in the fatty acid biosynthesis and metabolism pathway. FRK3 (AT1G66430) and CYT1 participate in more than one sugar metabolic pathway. TPS7 and SPSA1 enrich in starch and sucrose metabolism. ASE2 participates in the purine metabolic pathway.

\section{Discussion}

Plants regulate growth through metabolism and biosynthesis to acclimate to a changing external environment. The changes to structure and function of the cell membrane due to low temperatures result in an increase in membrane permeability, electrolyte extravasation, and relative electrical conductivity [30]. Membrane lipid peroxidation often occurs in plants under adverse conditions [36]. The content of the membrane lipid peroxidation product MDA can reflect the extent of cell membrane lipid peroxidation and the degree of damage to cells [31]. The membrane protein content of alfalf increased after cold acclimation for $2-3$ days at $4{ }^{\circ} \mathrm{C}$ [37]. A similar functioning protein in wheat, WPI6, is also a plasma membrane protein with two predicted membrane-spanning domains that play a protective role in maintaining plasma membrane function during cold acclimation [38]. These studies indicate that the stability of plant membrane proteins is very important for cold stress tolerance in plants.

Results from the qRT-PCR implied that the expression of genes were diminished in the mutant cor413-pm1, which confirmed the results of the proteomic analysis and suggested that proteins might be implicated in increasing plant tolerance to cold. Stability of the plasma membrane during freezing-induced dehydration is affected by many factors associated with endomembranes and cytoplasm, such as the chloroplast envelope lipid composition and accumulation of sugars [39]. FAB1 participates in fatty acid biosynthesis and metabolism (Figure 11 and Supplementary Table S2). Cell membrane fluidity is closely related to cold tolerance in plants [40]. An increase in unsaturated fatty acids can prevent lipid solidification at low temperatures [41]. The desaturation of fatty acids during chilling acclimation is one of the factors involved in conferring low-temperature tolerance in young tobacco leaves [41]. Plants with a high proportion of cis-unsaturated fatty acids are resistant to 
chilling, which has been demonstrated in spinach (Spinacia oleracea L.) and Arabidopsis [42]. Added oxidative stress leads to a decrease in membrane fluidity through an increase of free radicals [43]. The expression of $F A B 1$ was significantly lower in the mutant cor413-pm1, whether under normal conditions or subjected to freezing stress (Figure 10A). The mutant fab1 appeared to be susceptible to cellular damage caused by low temperatures $\left(2-6{ }^{\circ} \mathrm{C}\right)$ for long periods. The stress affected photosynthesis in $f a b 1$ by the degradation of its chloroplasts and consequently resulted in plant death. [44]. The mutant $f a b 1$ had increased levels of 16:0 fatty acids and concomitantly decreased levels of 18:0 fatty acids likely due to a mutation in the KAS2 (FAB1) gene, which caused a structural instability of the gene product during fatty acid synthesis $[45,46]$. Content of phosphatidylglycerol, associated with chilling stress, decreased by $10 \%$ in the mutant fab1 leaves compared with that of the WT Arabidopsis leaves [47]. Those results show that different fatty acid compositions, such as the ratio between saturated and unsaturated fatty acids, play key roles in acclimation to ambient temperatures. COR413-PM1 might affect the membrane structure through regulation of FAB1, which further determines the tolerance to freezing stress in Arabidopsis.

Sucrose is important for the maintenance of osmotic pressure in cellular metabolism as a signal molecule and in altering cell wall extensibility [48]. Fructose is a breakdown product of sucrose either by invertases or sucrose synthases [49]. Intensities of FRK3, SPSA1, CYT1, and TPS7 decreased due to the freezing treatment of cor413-pm1 and WT seedlings when compared to those of the respective seedlings of the control groups (Figure 10D-G). FRK3 (AT1G66430) and CYT1 participate in more than one kind of sugar metabolism (Figure 11 and Supplementary Table S2). TPS7 and SPSA1 enriches in starch and sucrose metabolism (Figure 11 and Supplementary Table S2). The FRK3/FRK6 gene, one of the seven main fructose-phosphorylating enzymes, is a single plastid-localized FRK [49]. Gas chromatography-mass spectrometry (GC-MS) was used to analyze the primary metabolic profile of the double-mutants of AtFRK6 and AtFRK7 seeds and revealed that TCA cycle organic acids and fatty acid metabolism decreased in these mutants [50]. The reduction of the UDP-glucose pool was observed by RNAi targeting of FRK2 in a hybrid aspen and resulted in thinner fibers and a lower proportion of cellulose in cell walls [51]. CYT1 is a key regulatory target in ascorbic acid (AsA) biosynthesis [52]. CYT1 encodes a GDP-mannose pyrophosphorylase which provides GDP-mannose, a principal component of cell wall carbohydrate biosynthesis. The CYT1 promoter was found to contain two DRE core sequences (ACCGAC) upstream of the transcription start site. Arabidopsis ethylene response factor 98 (AtERF98) can specifically bind to the DRE-2 fragment and acts as a positive regulator of CYT1 at the gene expression level [53]. The expression of the TPS gene in winter wheat subjected to various low-temperature treatments was measured with the Solexa sequencing platform, and a cluster analysis found that significantly higher gene expression was observed in varieties with strong tolerance than those with weak tolerance to low-temperature treatments. Furthermore, the TPS gene in wheat was involved in starch and sugar metabolism [54]. SPSA1 is one of the four SPS genes encoding sucrose-phosphate synthase (SPS) enzymes. Functional sucrose biosynthesis at low temperatures in overexpressing SPS plants reduced the inhibition of photosynthesis and increased the rate at which freezing tolerance developed [55]. Those results suggest that FRK3, CYT1, TPS7, and SPSA1 might be involved in tolerance to freezing stress in the mutant cor $413-p m 1$ and can affect cell wall extensibility through sugar metabolism.

It was shown that ASE2 participated in the purine metabolism pathway (Figure 11 and Supplementary Table S2). Purine nucleotides are directly involved in the synthesis of nucleic acids which serve as energy sources for plant growth [56]. The isozymes are encoded by the three genes ASE1 (AT2G16570), ASE2, and ASE3 (AT4G38880). Both ASE1 and ASE2 were localized to chloroplasts [57]. ASE2, one of the three ATase isozymes responsible for the first committed step of de novo purine biosynthesis, is not only important for cell division but also for chloroplast biogenesis [57]. There are direct interactions between the COR gene expression originating from a cold-induced signal transduction pathway and the redox state of the chloroplast [58,59]. ASE2 transgenic tobacco plants 
as well as Arabidopsis mutants exhibit strong growth retardation and severe chlorosis in leaves [60]. These results support the role of ASE2 in tolerance to freezing stress through purine metabolism.

The tolerance to freezing stress in the mutant cor $413-p m 1$ may be also influenced by abiotic stress and hormone signal transduction. It was reported that LSM4 genes were related to abscisic acid and osmotic stress signaling [61]. The loss of LSM4 lead to the growth retardation and greater sensitivity to salt. LSM4 was enriched in RNA degradation pathway. PYD1 initiated the degradation of uracil or thymine nucleobases [62]. The $A$. thaliana mutant $p y d 1$ exhibited delayed germination and seedling development and decreased cytosolic invertase activity that lead to an accumulation of sucrose [62]. The researchers assumed the interference of PYD1 with ABA signaling by the fact of ABA-responsive genes having been deregulated in pyd1 mutants and an increased PYD1 expression in wild type seedlings upon ABA treatment [62].

\section{Materials and Methods}

\subsection{Plant Materials and Growth Conditions}

Wild-type (WT) seeds of Arabidopsis ecotype Columbia-0 (Col-0) were preserved in the Key Laboratory of Biology and Genetic Improvement of Triticeae Crops, Ministry of Agriculture of China. Transfer DNA insertion lines of the mutant cor413-pm1 (SALK_014871, COR413-PM1, AT2G15970) were obtained from the Arabidopsis Biological Resource Center (ABRC) (Available online: http:/ / www.Arabidopsis.org). Loss-of-function of the mutant cor413-pm1 was confirmed by RT-PCR analysis. After WT and cor413-pm1 seeds were subjected to surface disinfection, they were sown on $\mathrm{MS}_{0}$ solid medium, refrigerated for $2-3$ days at $4{ }^{\circ} \mathrm{C}$, and then grown for 10 days in a culture chamber $\left(22^{\circ} \mathrm{C}\right.$, relative humidity $65 \%$, photoperiod $16 \mathrm{~h} / 8 \mathrm{~h}$ ). Seedlings were then transplanted to 140 -cm diameter by 120 -cm height pots with fertilized soil (vermiculite 2:1) and grown in a greenhouse $\left(22^{\circ} \mathrm{C}, 16 \mathrm{~h} / 8 \mathrm{~h}\right.$ light/dark cycle). After 14 days, at least four pots of each WT and cor $413-p m 1$ seedlings were moved into a refrigerator to expose seedlings to $\mathrm{a}-8^{\circ} \mathrm{C}$ freezing treatment for $1 \mathrm{~h}$. Four pots of each plant line, WT and cor413-pm1, grown at room temperature were used as control groups.

\subsection{Relative Electrical Conductivity}

Leaves of WT and cor413-pm1 seedlings $(0.03 \mathrm{~g})$ of both the control and freezing treatments were collected into $15 \mathrm{~mL}$ tubes containing $5 \mathrm{~mL}$ deionized water. They were vacuumed for $30 \mathrm{~min}$ with a CentriVap console (Labconco, Kansas City, MO, USA) and then sat for $45 \mathrm{~min}$ at room temperature. The electrical conductivity (EC) of each sample was measured as $S_{1}$, and deionized water without leaves was measured as $\mathrm{S}_{0}$. All samples were boiled for $10 \mathrm{~min}$ and then reduced to room temperature, and the final $\mathrm{EC}$ was measured as $\mathrm{S}_{2}$. The relative electrical conductivity was calculated as follows: $\mathrm{REC}=\left(\mathrm{S}_{1}-\mathrm{S}_{0}\right) /\left(\mathrm{S}_{2}-\mathrm{S}_{0}\right)[30]$.

\subsection{Protein Extraction}

The filter-aided sample preparation method (FASP) [63] was used to prepare the samples. After exposure to a $-8{ }^{\circ} \mathrm{C}$ freezing treatment for $1 \mathrm{~h}$ and a recovery period for $8 \mathrm{~h}$ at $22{ }^{\circ} \mathrm{C}, 50 \mathrm{mg}$ of Arabidopsis seedling shoot samples were placed in a 2-mL centrifuge tube with a steel ball and then added to liquid nitrogen for subsequent protein extraction. Cells in each sample were effectively pulverized in liquid nitrogen by using a Cell Disruption System (Retsch, Haan, Germany) for $1 \mathrm{~min}$ with a frequency of 20 times/s. They were then incubated with $400 \mu \mathrm{L}$ extraction buffer (8 M Urea, $2 \mathrm{mM}$ EDTA, $20 \mathrm{mM} \mathrm{CaCl}_{2}, 200 \mathrm{mM} \mathrm{NaCl}, 100 \mathrm{mM}$ Tris- $\mathrm{HCl}, \mathrm{pH}$ 8.1) and freeze-thawed 3-5 times. The crude extract was centrifuged at $13,000 \times g$ for $20 \mathrm{~min}$ at $4{ }^{\circ} \mathrm{C}$. The clear supernatant was loaded onto a filtration device (Amicon Ultra $0.5 \mathrm{~mL}$ Centrifugal Filters, $10 \mathrm{~K}$, Millipore, Burlington, MA, USA) and then centrifuged at $13,000 \times g$ for $25 \mathrm{~min}$ at $4{ }^{\circ} \mathrm{C}$. The filtrate was poured out from the outer tube. The filtration device was incubated for $60 \mathrm{~min}$ at $30^{\circ} \mathrm{C}$ on a shaker after $200 \mu \mathrm{L}$ DTT buffer (50 mM Dithiothreitol, $8 \mathrm{M}$ Urea, $100 \mathrm{mM}$ Tris-HCl, $\mathrm{pH}$ 8.1) was added in the inner tube for 
reduction of the disulfide bonds in the protein extracts. The incubated filtration device was centrifuged at $13,000 \times g$ for $30 \mathrm{~min}$ and then the filtrate was removed. The concentrate was diluted with $200 \mu \mathrm{L}$ UA buffer ( $8 \mathrm{M}$ Urea, $100 \mathrm{mM}$ Tris- $\mathrm{HCl}, \mathrm{pH}$ 8.1) and centrifuged three times to replace the DTT in each protein sample. Subsequently, freshly prepared IAA buffer (50 mM Iodoacetamide, $8 \mathrm{M}$ Urea, $100 \mathrm{mM}$ Tris- $\mathrm{HCl}, \mathrm{pH}$ 8.1) was added and then samples were incubated for $30 \mathrm{~min}$ at $30{ }^{\circ} \mathrm{C}$ in the dark. Then, the samples were centrifuged at $13,000 \times g$ for $30 \mathrm{~min}$. After three buffer exchanges with $8 \mathrm{M}$ Urea, the resulting concentrate was diluted two times with $100 \mu \mathrm{L} 50 \mathrm{mM} \mathrm{NH}_{4} \mathrm{HCO}_{3}$ solution. Finally, $50 \mu \mathrm{g}$ protein extract was digested with $0.5 \mu \mathrm{g}$ Trypsin (Promega, Mannheim, Germany) at 1:100 enzyme/protein concentration for $10 \mathrm{~h}$ at $37^{\circ} \mathrm{C}$. The enzyme cut samples were centrifuged at $13,000 \times g$ for 30 min with filtration devices. Ultrafiltration of the peptide mixture was collected and quantified based on the OD 280 values. The samples were directly injected for mass spectrometry analysis. Three biological replications were prepared in the study.

\subsection{Mass Spectrometric Analysis}

A label-free quantification (LFQ) mass spectrometry (MS) method was used to profile the Arabidopsis seedling shoot materials. For each run, $1 \mu \mathrm{L}$ peptides were loaded onto an Easy-nano1000 liquid chromatography (LC) system (Thermo Fisher Scientific, San Jose, CA, USA) equipped with a C18 PepMap trap precolumn $(100 \mu \mathrm{m} \times 20 \mathrm{~mm}$, Thermo Fisher Scientific). The eluted peptides were separated with a linear acetonitrile gradient $(3-90 \%$ over $90 \mathrm{~min}$ ) in $0.1 \%$ formic acid at a flow rate of $200 \mathrm{~nL} / \mathrm{min}$ on a C18 Tip column $(75 \mu \mathrm{m} \times 150 \mathrm{~mm}$, Thermo Fisher Scientific, San Jose, CA, USA) with a spray voltage of $2.3 \mathrm{kV}$. The peptide ions in the spray were analyzed in data-dependent acquisition mode on a Q-Excative Plus Orbitrap MS (Thermo Fisher Scientific, San Jose, CA, USA). The main parameter settings for the MS analysis are shown in Table 2.

Table 2. Main parameter settings for mass spectrometry (MS).

\begin{tabular}{ccccccc}
\hline Name & Resolution Ratio & AGC Target & Maximum IT ${ }^{\mathbf{1}}$ & Scan Range & Top N & NCE \\
\hline Full MS & 70,000 & $3 \times 10^{6}$ & $50 \mathrm{~ms}$ & $300-1800 \mathrm{~m} / z$ & $/$ & $/$ \\
dd-MS2 & 17,500 & $1 \times 10^{5}$ & $45 \mathrm{~ms}$ & $/$ & 20 & 27 \\
\hline \multicolumn{7}{c}{${ }^{1}$ injection time. }
\end{tabular}

\subsection{Protein Identification and Quantitation}

The qualitative analysis of identified proteins was performed with the Proteome Discoverer 2.1 software (PD, Thermo Fisher, Foster City, CA, USA). We conducted a plant genome search through the Arabidopsis Database (Available online: https://phytozome.jgi.doe.gov) using version Athaliana_167_TAIR10.protein. The qualitative search parameters were as follows: the confidence level of peptides was 6-144 amino acids in length and a maximum of two missed cleavages were allowed. The mass deviation of the parent ion was $\pm 10 \mathrm{ppm}$ and the mass deviation of the fragment ion was 0.02 Da. We used the iodoacetamide of cysteine (Cys) (carbamidomethyl/+57.021 Da) to fix the modification, with the variable modification by methionine (Met) oxidation (oxidation/+15.995 Da) and $N$-acetylation (Acetyl/ $+42.011 \mathrm{Da}$ ). The false discovery rate of peptide search was set to $1 \%$. Three replicates were retrieved together to obtain qualitative results for each plant group.

Maxquant version 1.3.0.5 software (Available online: http:/ / www.coxdocs.org) was used to conduct the quantitative analysis of identified proteins. The original data for each of the three replicates of each treatment group were selected for retrieval in the Arabidopsis Database as above. The search standards for the quantitative analysis were the same as those used in the qualitative analysis, such as the mass deviation of the fragment ion, the fixed modification, and the variable modification. Trypsin was used as the default protease and the precursor mass tolerance was $\pm 20 \mathrm{ppm}$. The minimum length of peptides that could be detected was seven amino acids. The false discovery rate of peptide search was set to 1\%. The data information was output in Excel. 
Pearson correlation analysis between the quantitation data of the four treatment groups (FT-cor413-pm1, C-cor413-pm1, FT-WT, C-WT) was performed using SPSS 22.0 data processing software (Available online: https://www.ibm.com/analytics). The degree of linear correlation for the four groups was represented by the absolute value.

\subsection{Bioinformatics Analysis}

The original data were preprocessed and standardized for quality control. They were then screened for reliable proteins based on the phenotypes of the mutant cor413-pm1 and WT and the intensities of DAPs. The $p$-value threshold was set to 0.05 . For screening DAPs, when the ratio of the signal intensity of a protein in a sample was greater than twofold or less than half of the signal intensity of the control sample, the protein was considered to be upregulated or downregulated, respectively. The GO biological functions of DAPs between the WT and the mutant cor413-pm1 were analyzed by Gene Ontology (Available online: http:/ / www.geneontology.org/). We conducted KEGG Pathway and enrichment analyses of DAPs using the Kyoto Encyclopedia of Genes and Genomes (KEGG) Pathway (Available online: http://www.kegg.jp/). The protein-protein interaction (PPI) analysis was carried out using the Search Tool for the Retrieval of Interacting Genes (STRING) database (Available online: https://string-db.org/cgi/input.pl).

\subsection{RNA Isolation and Quantitative Real-Time PCR ( $q R T-P C R)$}

Total RNA was isolated from Arabidopsis using an RNAprep Pure Plant Kit (Tiangen, Beijing, China). Complementary DNA (cDNA) was synthesized using a One-Step gDNA Removal and cDNA Synthesis SuperMix (TransGen Biotech, Beijing, China). The quantitative RT-PCR was implemented using SuperReal PreMix Plus (SYBR Green) (Tiangen, Beijing, China) with an Applied Biosystems ABI 7500 Real-Time PCR System (Thermo Fisher Scientific, San Jose, MA, USA). Each reaction had three replicates.

\subsection{Accession Codes}

The mass spectrometry proteomics data have been deposited to the ProteomeXchange Consortium [64] via the PRIDE [65] partner repository (Available online: http:/ / proteomecentral. proteomexchange.org) with the dataset identifier PXD010031.

\section{Conclusions}

The results indicate that the multispanning transmembrane protein COR413-PM1 plays an important role in conferring freezing tolerance in Arabidopsis. The mutant cor413-pm1 showed greater damage to the cellular membrane system under freezing temperatures. The multispanning transmembrane protein COR413-PM1 confirm that the stability of plant membrane proteins is very important for cold stress tolerance in plants. The DAPs are involved in a number of physiological processes and act together to create a new equilibrium when plants are exposed to freezing temperatures. The study of the dynamic changes of proteins in WT and cor413-pm1 furthers our understanding of the mechanisms of COR413-PM1 at the protein level in response to freezing temperature stress. Three proteins, FAB1, ASE2, and LSM4, were identified and were associated with freezing treatment. The fatty acid metabolism which FAB1 enriched might influence the plasma membrane structure to affect the freezing stress tolerance. Several proteins, including FRK3, SPSA1, CYT1, and TPS7, enriched in sugar metabolism may influence the ability of osmotic adjustment in plants under freezing stress. ASE2 participated in the purine metabolism pathway, which serves as an energy source for plant growth. LSM4 and PYD1 were related to abiotic stress, such as those posed by abscisic acid or salt. Changes in temperature modify the balance of energy absorbed and metabolized in individuals. The interaction between photosynthetic redox, cold acclimation, sugar-signaling pathways, and other processes regulate plant acclimation to low temperatures [59]. Although there are few studies on the membrane localization proteins' response to low-temperature 
stress, we firstly indicate that the multispanning transmembrane protein COR413-PM1 plays an important role in the process of low-temperature stress response in plants. The DAPs associated with COR413-PM1 and freezing treatment were mainly involved in the metabolisms of fatty acids, sugars, and purine. The verification confirmed the proteomic analysis results of four proteins: FAB1, FRK3, SPSA1, and ASE2. As different related proteins were identified, it shows that the complexity of plant signal transduction pathways and freezing tolerance may indicate polygenic controls in Arabidopsis.

Supplementary Materials: Supplementary materials can be found at http:/ /www.mdpi.com/1422-0067/19/9/ 2572/s1.

Author Contributions: Y.X., M.C., and Y.P. designed the research experiments; Y.X., M.C., Y.M., and Z.X. supervised the experiments; Y.P., C.S., Y.M., M.Z., and B.M. performed the experiments and analyzed the data; K.C., Q.D., and R.Y. provided experimental assistance to C.S.; C.S. drafted the manuscript and prepared the figures and tables with contributions from all the authors. All authors read and approved the final manuscript.

Acknowledgments: This work was supported by the National Key Project for Research on Transgenic Biology [2016ZX08002-002] and the Agricultural Science and Technology Innovation Program (ASTIP, Transgenic Technology and Application of Crops, and Development and Application of Molecular Markers in Crops).

Conflicts of Interest: The authors declare no conflict of interest.

\section{Abbreviations}

$\begin{array}{ll}\text { COR } & \text { Cold-regulated } \\ \text { MDA } & \text { Malondialdehyde } \\ \text { MS } & \text { Mass Spectrometry } \\ \text { DAPs } & \text { Differentially Abundant Proteins } \\ \text { GO } & \text { Gene Ontology } \\ \text { KEGG } & \text { Kyoto Encyclopedia of Genes and Genomes } \\ \text { qRT-PCR } & \text { quantitative Real-Time Polymerase Chain Reaction }\end{array}$

\section{References}

1. Chinnusamy, V.; Zhu, J.; Zhu, J.K. Cold stress regulation of gene expression in plants. Trends Plant Sci. 2007, 12, 444-451. [CrossRef] [PubMed]

2. Zhang, N.; Huo, W.; Zhang, L.; Chen, F.; Cui, D. Identification of winter-responsive proteins in bread wheat using proteomics analysis and virus-induced gene silencing. Mol. Cell. Proteom. 2016, 15, 2954-2969. [CrossRef] [PubMed]

3. Viswanathan, C.; Zhu, J.-K. Molecular genetic analysis of cold-regulated gene transcription. Philos. Trans. R. Soc. Lond. B Biol. Sci. 2002, 357, 877-886. [CrossRef] [PubMed]

4. Thomashow, M.F. Plant Cold Acclimation: Freezing tolerance genes and regulatory mechanisms. Annu. Rev. Plant Physiol. Plant Mol. Biol. 1999, 50, 571-599. [CrossRef] [PubMed]

5. Browse, J.; Xin, Z. Temperature sensing and cold acclimation. Curr. Opin. Plant Biol. 2001, 4, $241-246$. [CrossRef]

6. Stockinger, E.J.; Gilmour, S.J.; Thomashow, M.F. Arabidopsis thaliana CBF1 encodes an AP2 domain-containing transcriptional activator that binds to the C-repeaty/DRE, a cis-acting DNA regulatory element that stimulates transcription in response to low temperature and water deficit. Proc. Natl. Acad. Sci. USA 1997, 94, 1035-1040. [CrossRef] [PubMed]

7. Liu, Q.; Kasuga, M.; Sakuma, Y.; Abe, H.; Miura, S.; Yamaguchi-Shinozaki, K.; Shinozakib, K. Two transcription factors, DREB1 and DREB2, with an EREBP/AP2 DNA binding domain separate two cellular signal transduction pathways in drought- and low-temperature-responsive gene expression, respectively, in Arabidopsis. Plant Cell 1998, 10, 1391-1406. [CrossRef] [PubMed]

8. Kosová, K.; Vítámvás, P.; Prášil, I.T.; Renaut, J. Plant proteome changes under abiotic stress-contribution of proteomics studies to understanding plant stress response. J. Proteom. 2011, 74, 1301-1322. [CrossRef] [PubMed]

9. Apel, K.; Hirt, H. Reactive oxygen species: Metabolism, oxidative stress, and signal transduction. Annu. Rev. Plant Biol. 2004, 55, 373-399. [CrossRef] [PubMed] 
10. Hannah, M.A.; Wiese, D.; Freund, S.; Fiehn, O.; Heyer, A.G.; Hincha, D.K. Natural genetic variation of freezing tolerance in Arabidopsis. Plant Physiol. 2006, 142, 98-112. [CrossRef] [PubMed]

11. Wanner, L.A.; Junttila, O. Cold-induced freezing tolerance in Arabidopsis. Plant Physiol. 1999, 120, $391-399$. [CrossRef] [PubMed]

12. Xin, Z.; Browse, J. Cold comfort farm: The acclimation of plants to freezing temperatures. Plant Cell Environ. 2000, 23, 893-902. [CrossRef]

13. Sung, D.-Y.; Kaplan, F.; Lee, K.-J.; Guy, C.L. Acquired tolerance to temperature extremes. Trends Plant Sci. 2003, 8, 179-187. [CrossRef]

14. Lee, B.-H.; Henderson, D.A.; Zhu, J.-K. The Arabidopsis cold-responsive transcriptome and its regulation by ICE1. Plant Cell 2005, 17, 3155-3175. [CrossRef] [PubMed]

15. Vogel, J.T.; Zarka, D.G.; Buskirk, H.A.V.; Fowler, S.G.; Thomashow, M.F. Roles of the CBF2 and ZAT12 transcription factors in configuring the low temperature transcriptome of Arabidopsis. Plant J. 2005, 41, 195-211. [CrossRef] [PubMed]

16. Seki, M.; Ishida, J.; Narusaka, M.; Fujita, M.; Nanjo, T.; Umezawa, T.; Kamiya, A.; Nakajima, M.; Enju, A.; Sakurai, T. Monitoring the expression pattern of around 7000 Arabidopsis genes under ABA treatments using a full-length cDNA microarray. Funct. Integr. Genom. 2002, 2, 282-291. [CrossRef] [PubMed]

17. Yamaguchi-Shinozaki, K.; Shinozaki, K. A novel cis-acting element in an Arabidopsis gene is involved in responsiveness to drought, low temperature or high salt stress. Plant Cell 1994, 6, 251-264. [CrossRef] [PubMed]

18. Chen, L.; Zhong, H.; Ren, F.; Guo, Q.-Q.; Hu, X.-P.; Li, X.-B. A novel cold-regulated gene, COR25, of Brassica napus is involved in plant response and tolerance to cold stress. Plant Cell Rep. 2011, 30, 463-471. [CrossRef] [PubMed]

19. Breton, G.; Danyluk, J.; Charron, J.-B.F.; Sarhan, F. Expression profiling and bioinformatic analyses of a novel stress-regulated multispanning transmembrane protein family from cereals and Arabidopsis. Plant Physiol. 2003, 132, 64-74. [CrossRef] [PubMed]

20. Machuka, J.; Bashiardes, S.; Ruben, E.; Spooner, K.; Cuming, A.; Knight, C.; Cove, D. Sequence analysis of expressed sequence tags from an ABA-treated cDNA 1ibrary identifies stress response genes in the moss Physcomitrella patens. Plant Cell Physiol. 1999, 40, 378-387. [CrossRef] [PubMed]

21. Orvar, B.L.; Sangwan, V.; Omann, F.; Dhindsa, R.S. Early steps in cold sensing by plant cells: The role of actin cytoskeleton and membrane fluidity. Plant J. 2000, 23, 785-794. [CrossRef] [PubMed]

22. Sangwan, V.; Foulds, I.; Singh, J.; Dhindsa, R.S. Cold-activation of Brassica napus BN115 promoter is mediated by structural changes in membranes and cytoskeleton, and requires $\mathrm{Ca}^{2+}$ influx. Plant J. 2001, 27, 1-12. [CrossRef] [PubMed]

23. Thalhammer, A.; Hundertmark, M.; Popova, A.V.; Seckle, R.; Hincha, D.K. Interaction of two intrinsically disordered plant stress proteins (COR15A and COR15B) with lipid membranes in the dry state. Biochim. Biophys. Acta 2010, 1798, 1812-1820. [CrossRef] [PubMed]

24. Artus, N.N.; Uemura, M.; Steponkus, P.L.; Gilmour, S.J.; Lin, C.; Thomashow, M.F. Constitutive expression of the cold-regulated Arabidopsis thaliana COR15a gene affects both chloroplast and protoplast freezing tolerance. Proc. Natl. Acad. Sci. USA 1996, 93, 13404-13409. [CrossRef] [PubMed]

25. Gilmour, S.J.; Artus, N.N.; Thomashow, M.F. cDNA sequence analysis and expression of two cold-regulated genes of Arabidopsis thaliana. Plant Mol. Biol. 1992, 18, 13-21. [CrossRef] [PubMed]

26. Danyluk, J.; Perron, A.; Houde, M.; Limin, A.; Fowler, B.; Benhamou, N.; Sarhan, F. Accumulation of an acidic dehydrin in the vicinity of the plasma membrane during cold acclimation of wheat. Plant Cell 1998, 10, 623-638. [CrossRef] [PubMed]

27. Janmohammadi, M.; Zolla, L.; Rinalducci, S. Low temperature tolerance in plants: Changes at the protein level. Phytochemistry 2015, 117, 76-89. [CrossRef] [PubMed]

28. Bouché, N.; Bouchez, D. Arabidopsis gene knockout: Phenotypes wanted. Curr. Opin. Plant Biol. 2001, 4, 111-117. [CrossRef]

29. Parinov, S.; Sundaresan, V. Functional genomics in Arabidopsis: Large-scale insertional mutagenesis complements the genome sequencing project. Curr. Opin. Biotechnol. 2000, 11, 157-161. [CrossRef]

30. Jiang, B.; Shi, Y.; Zhang, X.; Xin, X.; Qi, L.; Guo, H.; Li, J.; Yang, S. PIF3 is a negative regulator of the CBF pathway and freezing tolerance in Arabidopsis. Proc. Natl. Acad. Sci. USA 2017, 114, E6695-E6702. [CrossRef] [PubMed] 
31. Wang, S.; Liang, D.; Li, C.; Hao, Y.; Ma, F.; Shu, H. Influence of drought stress on the cellular ultrastructure and antioxidant system in leaves of drought-tolerant and drought-sensitive apple rootstocks. Plant Physiol. Biochem. 2012, 51, 81-89. [CrossRef] [PubMed]

32. Bogeat-Triboulot, M.-B.; Brosche, M.; Renaut, J.; Jouve, L.; Thiec, D.L.; Fayyaz, P.; Vinocur, B.; Witters, E.; Laukens, K.; Teichmann, T. Gradual soil water depletion results in reversible changes of gene expression, protein profiles, ecophysiology, and growth performance in Populus euphratica, a poplar growing in arid regions. Plant Physiol. 2007, 143, 876-892. [CrossRef] [PubMed]

33. Gygi, S.P.; Rochon, Y.; Franza, B.R.; Aebersold, R. Correlation between protein and mRNA abundance in yeast. Mol. Cell. Biol. 1999, 19, 1720-1730. [CrossRef] [PubMed]

34. Renauta, J.; Hausman, J.-F.; Wisniewski, M.E. Proteomics and low-temperature studies: Bridging the gap between gene expression and metabolism. Physiol. Plant. 2006, 126, 97-109. [CrossRef]

35. Abdelmegid, S.; Murugaiyan, J.; Abo-Ismail, M.; Caswell, J.L.; Kelton, D.; Kirby, G.M. Identification of host defense-related proteins using label-free quantitative proteomic analysis of milk whey from cows with staphylococcus aureus subclinical mastitis. Int. J. Mol. Sci. 2017, 19. [CrossRef] [PubMed]

36. Maki, K.; Takeshi, O.; Bunichi, E. Salt stress-induced lipid peroxidation is reduced by glutathione S-transferase, but this reduction of lipid peroxides is not enough for a recovery of root growth in Arabidopsis. Plant Sci. 2005, 169, 369-373. [CrossRef]

37. Mohapatra, S.S.; Poole, R.J.; Dhindsa, R.S. Alterations in membrane protein-profile during cold treatment of Alfalfa. Plant Physiol. 1988, 86, 1005-1007. [CrossRef] [PubMed]

38. Imai, R.; Koike, M.; Sutoh, K.; Kawakami, A.; Torada, A.; Oono, K. Molecular characterization of a cold-induced plasma membrane protein gene from wheat. Mol. Genet. Genom. 2005, 274, 445-453. [CrossRef] [PubMed]

39. Uemura, M.; Steponkus, P.L. Cold acclimation in plants: Relationship between the lipid composition and the cryostability of the plasma membrane. J. Plant Res. 1999, 112, 245-254. [CrossRef]

40. Lyons, J.M.; Asmundson, C.M. Solidification of unsaturated/saturated fatty acid mixtures and its relationship to chilling sensitivity in plants. J. Am. Oil Chem. Soc. 1965, 42, 1056-1058. [CrossRef] [PubMed]

41. Kodama, H.; Horiguchi, C.; Nishiuchi, T.; Nishimura, M.; Iba, K. Fatty acid desaturation during chilling acclimation is one of the factors involved in conferring low-temperature tolerance to young tobacco leaves. Plant Physiol. 1995, 107, 1177-1185. [CrossRef] [PubMed]

42. Murata, N.; Ishizaki-Nishizawa, O.; Higashi, S.; Hayashi, H.; Tasaka, Y.; Nishida, I. Genetically engineered alteration in the chilling sensitivity of plants. Nature 1992, 356, 710-713. [CrossRef]

43. Yehuda, S.; Rabinovitz, S.; Carasso, R.L.; Mostofsky, D.I. The role of polyunsaturated fatty acids in restoring the aging neuronal membrane. Neurobiol. Aging 2002, 23, 843-853. [CrossRef]

44. Wu, J.; Lightner, J.; Warwick, N.; Browse, J. Low-temperature damage and subsequent recovery of fab1 mutant Arabidopsis exposed to $2^{\circ} \mathrm{C}$. Plant Physiol. 1997, 113, 347-356. [CrossRef] [PubMed]

45. Carlsson, A.S.; LaBrie, S.T.; Kinney, A.J.; Wettstein-Knowles, P.; Browse, J. A KAS2 cDNA complements the phenotypes of the Arabidopsis fab1 mutant that differs in a single residue bordering the substrate binding pocket. Plant J. 2002, 29, 761-770. [CrossRef] [PubMed]

46. Wu, J.; James, D.W., Jr.; Dooner, H.K.; Browse, J. A mutant of Arabidopsis deficient in the elongation of palmitic acid. Plant Physiol. 1994, 106, 143-150. [CrossRef] [PubMed]

47. Gao, J.; Wallis, J.G.; Browse, J. Mutations in the prokaryotic pathway rescue the fatty acid biosynthesis 1 mutant in the cold. Plant Physiol. 2015, 169, 442-452. [CrossRef] [PubMed]

48. Sturm, A. Invertases. primary structures, functions, and roles in plant development and sucrose partitioning. Plant Physiol. 1999, 121, 1-7. [CrossRef] [PubMed]

49. Riggs, J.W.; Cavales, P.C.; Chapiro, S.M.; Callis, J. Identification and biochemical characterization of the fructokinase gene family in Arabidopsis thaliana. BMC Plant Biol. 2017, 17, 83. [CrossRef] [PubMed]

50. Stein, O.; Avin-Wittenberg, T.; Krahnert, I.; Zemach, H.; Bogol, V.; Daron, O.; Aloni, R.; Fernie, A.R.; Granot, D. Arabidopsis fructokinases are important for seed oil accumulation and vascular development. Front. Plant Sci. 2017, 7, 2047. [CrossRef] [PubMed]

51. Roach, M.; Gerber, L.; Sandquist, D.; Gorzsas, A.; Hedenstrom, M.; Kumar, M.; Steinhauser, M.C.; Feil, R.; Daniel, G.; Stitt, M. Fructokinase is required for carbon partitioning to cellulose in aspen wood. Plant J. 2012, 70, 967-977. [CrossRef] [PubMed] 
52. Zhao, S.; Liua, L. Expression and crystallographic studies of the Arabidopsis thaliana GDP-D-mannose pyrophosphorylase VTC1. Acta Crystallogr. F Struct Biol. Commun. 2016, 72, 795-798. [CrossRef] [PubMed]

53. Zhang, Z.; Wang, J.; Zhang, R.; Huang, R. The ethylene response factor AtERF98 enhances tolerance to salt through the transcriptional activation of ascorbic acid synthesis in Arabidopsis. Plant J. 2012, 71, 273-287. [CrossRef] [PubMed]

54. Xie, D.; Li, Z. Transcriptome profile and differentially expressed genes analysis in winter wheat under cold stress conditions. Res. J. Biotechnol. 2015, 10, 73-88.

55. Strand, A.; Foyer, C.H.; Gustafsson, P.; Gardestrom, P.; Hurry, V. Altering flux through the sucrose biosynthesis pathway in transgenic Arabidopsis thaliana modifies photosynthetic acclimation at low temperatures and the development of freezing tolerance. Plant Cell Environ. 2003, 26, 523-535. [CrossRef]

56. Stasolla, C.; Katahira, R.; Thorpe, T.A.; Ashihara, H. Purine and pyrimidine nucleotide metabolism in higher plants. J. Plant Physiol. 2003, 160, 1271-1295. [CrossRef] [PubMed]

57. Hung, W.F.; Chen, L.J.; Boldt, R.; Sun, C.W.; Li, H.M.; Hung, W.-F.; Chen, L.-J.; Boldt, R.; Sun, C.-W.; Li, H.-M. Characterization of Arabidopsis glutamine phosphoribosyl pyrophosphate amidotransferase-deficient mutants. Plant Physiol. 2004, 135, 1314-1323. [CrossRef] [PubMed]

58. Rapacz, M.; Wolanin, B.; Hura, K.; Tyrka, M. The effects of cold acclimation on photosynthetic apparatus and the expression of COR14b in four genotypes of barley (Hordeum vulgare) contrasting in their tolerance to freezing and high-light treatment in cold conditions. Ann. Bot. 2008, 101, 689-699. [CrossRef] [PubMed]

59. Ensminger, I.; Busch, F.; Huner, N.P.A. Photostasis and cold acclimation: Sensing low temperature through photosynthesis. Physiol. Plant. 2006, 126, 28-44. [CrossRef]

60. Van der Graaff, E.; Hooykaas, P.; Lein, W.; Lerchl, J.; Kunze, G.; Sonnewald, U.; Boldt, R. Molecular analysis of "de novo" purine biosynthesis in solanaceous species and in Arabidopsis thaliana. Front. Biosci. 2004, 9 , 1803-1816. [CrossRef] [PubMed]

61. Zhang, Z.; Zhang, S.; Zhang, Y.; Wang, X.; Li, D.; Li, Q.; Yue, M.; Li, Q.; Zhang, Y.-E.; Xu, Y. Arabidopsis floral initiator SKB1 confers high salt tolerance by regulating transcription and pre-mRNA splicing through altering histone H4R3 and small nuclear ribonucleoprotein LSM4 methylation. Plant Cell 2011, 23, 396-411. [CrossRef] [PubMed]

62. Cornelius, S.; Witz, S.; Rolletschek, H.; Mohlmann, T. Pyrimidine degradation influences germination seedling growth and production of Arabidopsis seeds. J. Exp. Bot. 2011, 62, 5623-5632. [CrossRef] [PubMed]

63. Wisniewski, J.R.; Zougman, A.; Nagaraj, N.; Mann, M. Universal sample preparation method for proteome analysis. Nat. Methods 2009, 6, 359-362. [CrossRef] [PubMed]

64. Deutsch, E.W.; Csordas, A.; Sun, Z.; Jarnuczak, A.; Perez-Riverol, Y.; Ternent, T.; Campbell, D.S.; Bernal-Llinares, M.; Okuda, S.; Kawano, S. The ProteomeXchange consortium in 2017: Supporting the cultural change in proteomics public data deposition. Nucleic Acids Res. 2017, 45, D1100-D1106. [CrossRef] [PubMed]

65. Vizcaino, J.A.; Csordas, A.; del-Toro, N.; Dianes, J.A.; Griss, J.; Lavidas, I.; Mayer, G.; Perez-Riverol, Y.; Reisinger, F.; Ternent, T. 2016 update of the PRIDE database and its related tools. Nucleic Acids Res. 2016, 44, D447-D456. [CrossRef] [PubMed]

(C) 2018 by the authors. Licensee MDPI, Basel, Switzerland. This article is an open access article distributed under the terms and conditions of the Creative Commons Attribution (CC BY) license (http://creativecommons.org/licenses/by/4.0/). 